\title{
EFFECTS OF JOINT PREPARATION ANGLE OF SINGLE-VEE BUTT WELDS ON THE TENSILE STRENGTH OF ASTM A36 CARBON STEEL
}

\author{
A Master's Thesis \\ Presented to \\ The College of Graduate and Professional Studies \\ Department of Applied Engineering \& Technology Management \\ Indiana State University \\ Terre Haute, Indiana \\ In Partial Fulfillment \\ of the Requirements for the Degree \\ Master of Science Degree \\ by \\ Matthew McClure \\ May 2011 \\ (C) Matthew McClure 2011
}

Keywords: Tension, Preparation Angle, Single-Vee, Butt Joint, Weld 


\section{Committee Members}

Committee Chair: Dr. A. Mehran Shahhosseini

Assistant Professor, Department of Applied Engineering and Technology Management

Indiana State University

Committee Member: Dr. Phillip Cochrane

Assistant Professor, Department of Applied Engineering and Technology Management

Indiana State University

Committee Member: Mr. Todd Alberts

Instructor, Department of Applied Engineering and Technology Management

Indiana State University 


\begin{abstract}
Welding is a multi-faceted procedure of manufacturing and can occur at any point during the creation of a product. Quality issues in welding can have disastrous, or even deadly, consequences. The issue of weld preparation angle is one of several different elements that have a direct correlation on the quality of a welded joint. The purpose of this research centers on resultant tensile strength of a single-vee butt joint in carbon steel with various preparation angles.

Preparation angles were machined on twenty-six pieces of ASTM A36 carbon steel in $5^{\circ}$ increments in order to produce thirteen samples with included preparation angles ranging from $0^{\circ}$ to $120^{\circ}$. Test samples were developed using an automated welding process that remained consistent for all of the welds. Each sample was plasma cut into ten coupons, which were machined to have a uniform cross section of the welded joint and surrounding parent material using a computer numerically controlled machining center. This yielded a total population of 130 coupons, which were tested to failure using a United Testing Systems stress/strain tensile tester.
\end{abstract}

The empirical data were analyzed via the use of SPSS 18 statistical software. Initially, the level of population variance was assessed within groups and between groups by use of a oneway ANOVA test at the .05 alpha level. The result showed a statistically significant difference of the sample population. Secondly, a comparison of the data at various preparation angles to that of the industry standard angle of $60^{\circ}$ was assessed using a Bonferroni multiple comparisons 
at the .05 alpha level, which resulted in one angle being statistically significant compared to the industry standard. 


\section{Acknowledgements}

A task such as this is formidable and complex, and cannot be done alone. I would formally like to offer my thanks to the following individuals in their efforts towards helping me reach my goals. I wish to distinguish those who supported me in this research endeavor as an essential key in the successful completion of this project, and offer my gratitude for your collaboration, encouragement, and technical expertise.

It is with much appreciation that I recognize the efforts of my graduate research committee members Dr. A. Mehran Shahhosseini, Mr. Todd Alberts, and Dr. Phillip Cochrane. Their guidance and support has been instrumental in the completion of this research in a manner that offered both scholastic and technical excellence. They have provided direction and leadership that assisted my effort academically, professionally, and personally. I am grateful for the opportunity to have worked with them.

I would also like to thank Mr. Mark Clauss and Mr. Scott Livengood for their knowledge and assistance during testing. Without their help, this research would have not been completed in the limited time that was available.

I would like to offer my gratitude to the ISU School of Graduate Studies for their monetary support to fund the purchase of materials and consumable goods necessary to the project through the Graduate Student Research Fund. Also, the College of Technology within Indiana State University is recognized for their contributions of materials and machining equipment. 
Finally, I would also like to thank my family, friends, and co-workers who offered their continual support and encouragement during the long hours required to complete this project. 


\section{Table of Contents}

Page

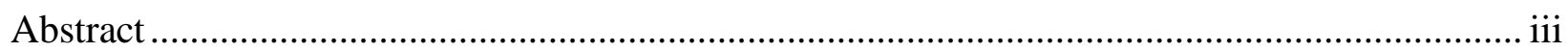

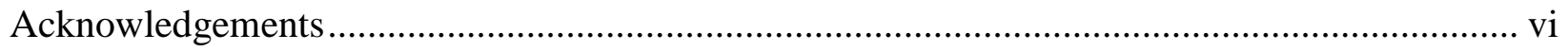

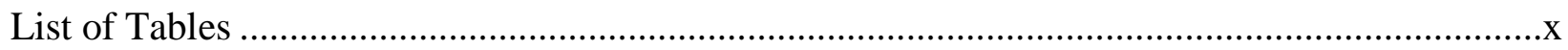

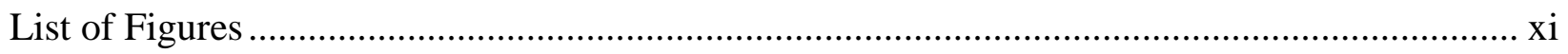

Effects of Joint Preparation Angle of Single-Vee Butt Welds on the Tensile Strength of ASTM

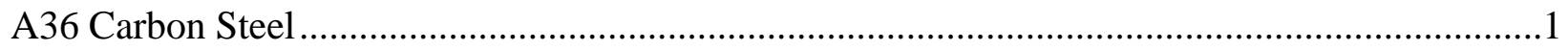

Statement of the Hypothesis ..................................................................................... 2

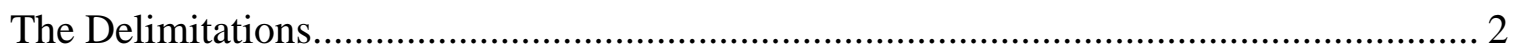

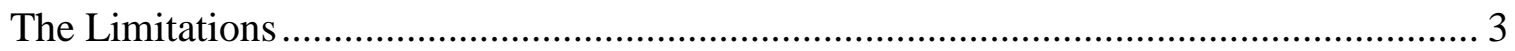

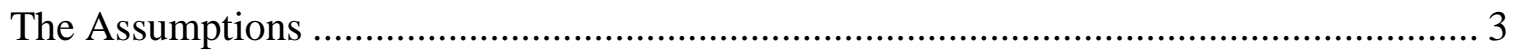

Terminology

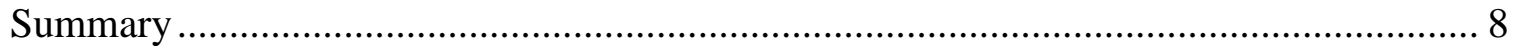

Review of literature

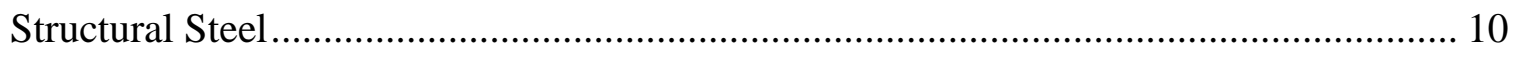

Fusion Welding Process....................................................................................... 11

The Structures of the Welded Joint.............................................................................. 12

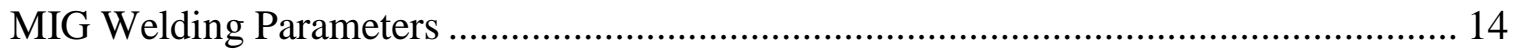

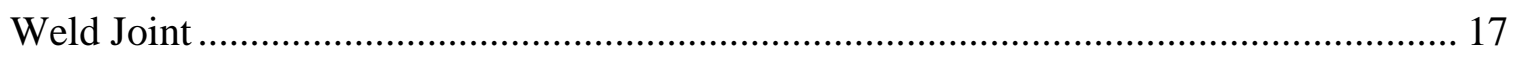


Weld Failure Analysis and Prevention ................................................................ 20

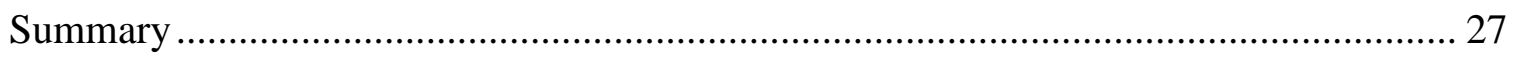

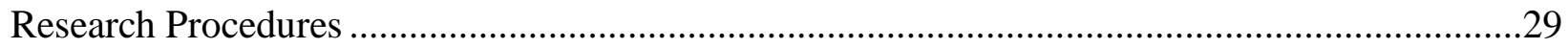

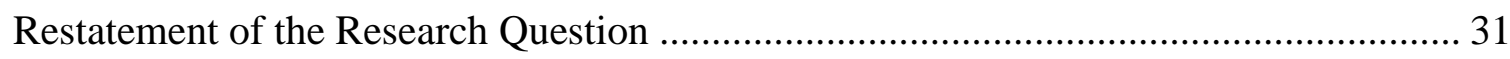

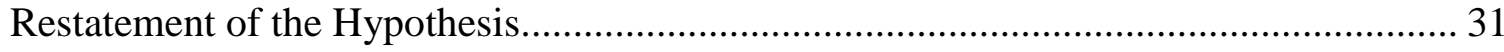

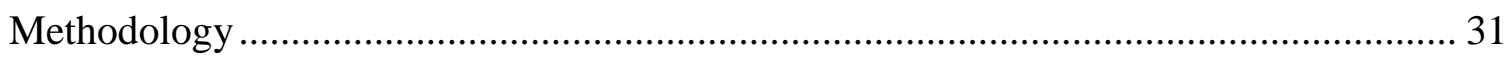

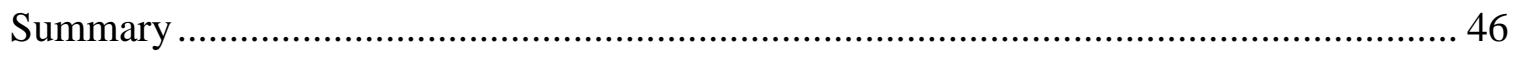

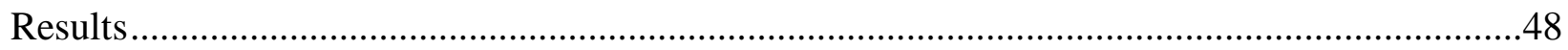

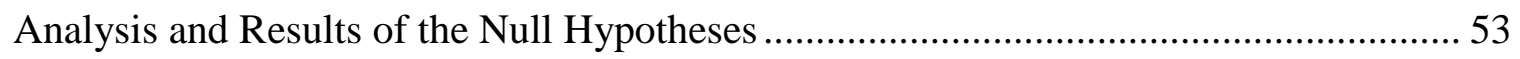

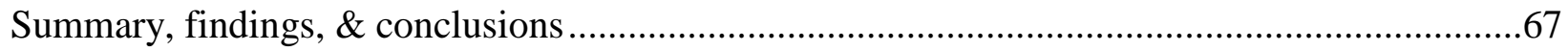

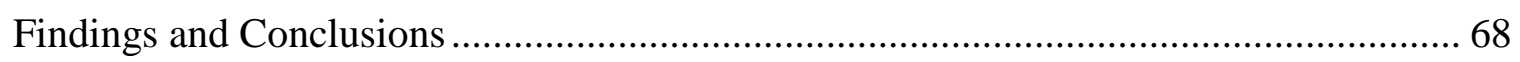

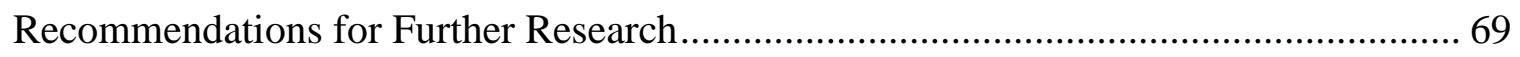

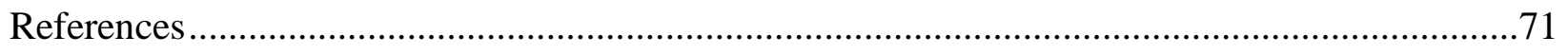

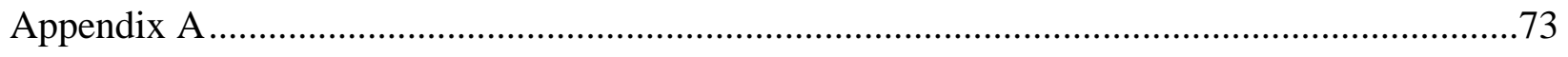

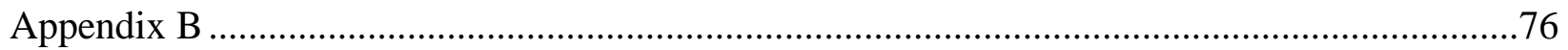




\section{List of Tables}

Table

Page

1. Material Properties of ASTME A36 Steel ......................................................................... 10

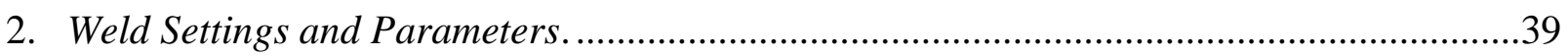

3. Tensile Strength Values at Each Preparation Angle ......................................................49

4. Levene Test of Homogeneity of Variances ...................................................................56

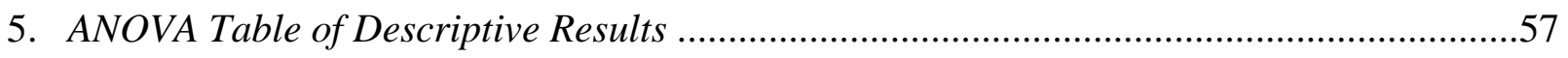

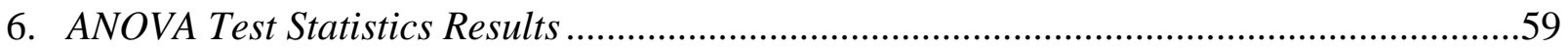

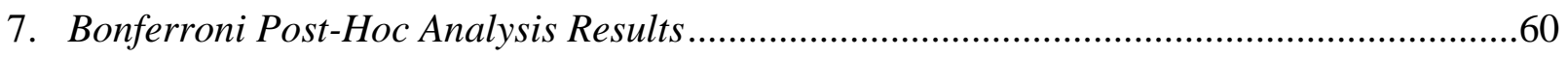




\section{List of Figures}

Figure $\quad$ Page

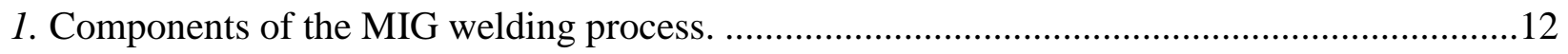

2. Schematic of the MIG welding process showing torch, weld, and electrical hookup.............13

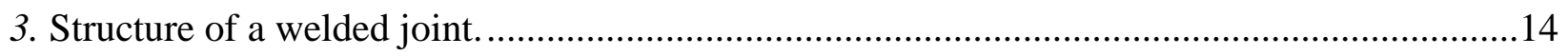

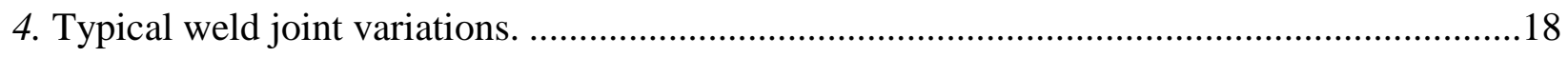

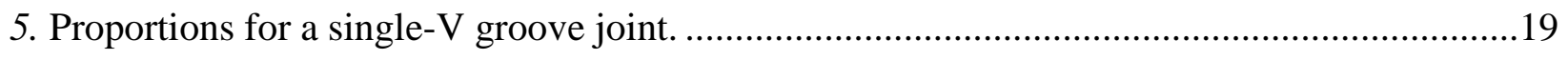

6. Incomplete penetration of a welded single-V butt joint...................................................19

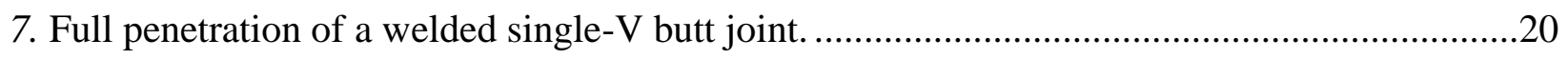

8. Typical required division of a test plate and the locations of the test specimens..................23

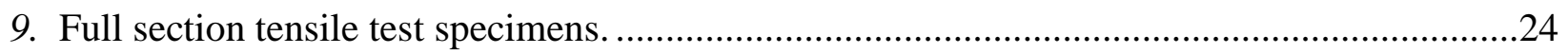

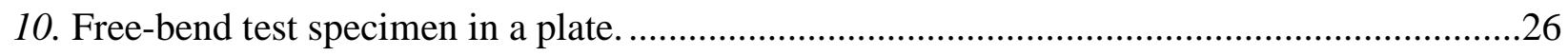

11. Method for initial bend for free-bend test specimens. .................................................26

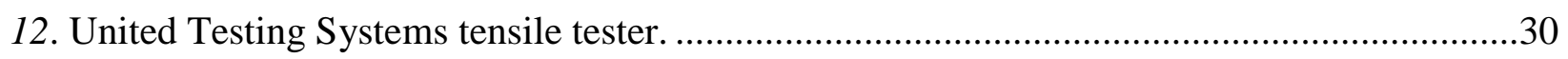

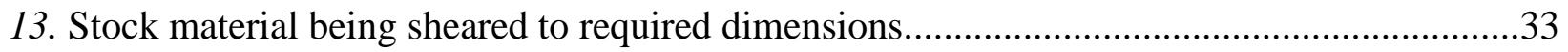

14. Dimensions of stock material for machining and testing...........................................33

15. Stop used during the shearing process to control length of the samples. .............................34

16. Machining of initial sample at $60^{\circ}$ included preparation angle........................................35

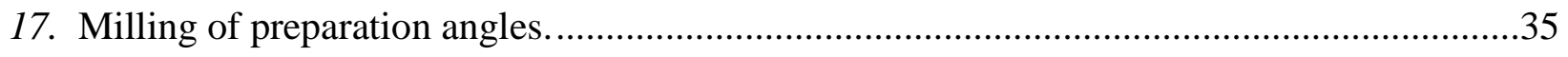


18. Vernier angle meter used to further ensure preparation angle accuracy..............................37

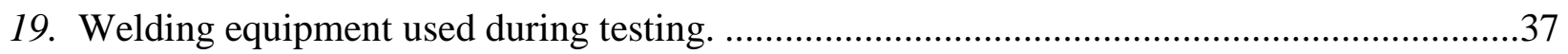

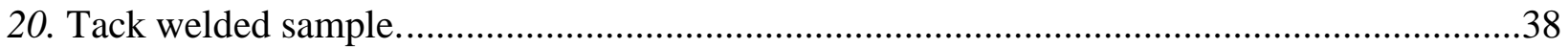

21. Cracking at weld joint due to shearing process. ....................................................... 40

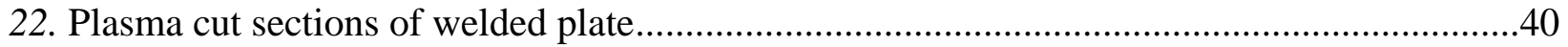

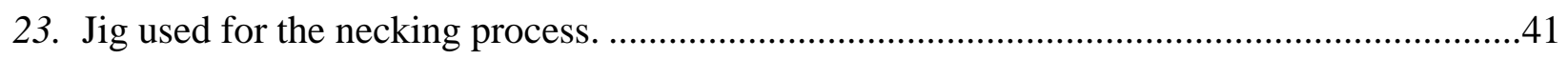

24. Okuma MC-3V Computer Numerical Control center. ...................................................42

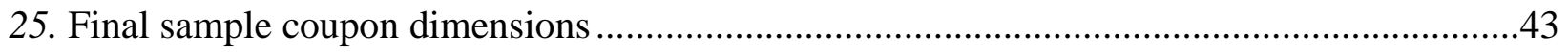

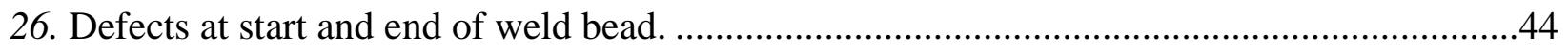

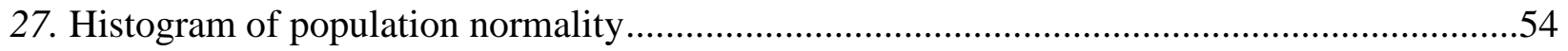

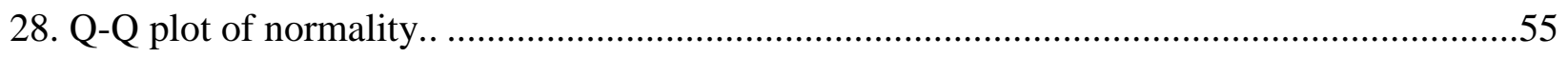

29. Standard plot of between group means within ANOVA …................................................58 


\section{Chapter 1}

\section{Effects of Joint Preparation Angle of Single-Vee Butt Welds on the Tensile Strength of ASTM A36 Carbon Steel}

The effects of different preparation angles used to achieve full penetration of a welded butt joint are unknown. The industry standard for the included angle of edge preparation on a given thickness of a material is $60^{\circ}$, which is used to obtain full penetration of the weld in the joint. Full penetration allows the joint to obtain the maximum potential strength and physical properties of the joint. If only partial penetration is achieved, the strength of the join may be reduced (Davies, The Science and Practice of Welding, 1984). Of interest to the researcher is if there is a statistically significant difference in a given range of the preparation angle at the joint related to the tensile strength of the sample. Secondarily, it is also of interest at what preparation angles do the differences in tensile strength become statistically significant. This experiment was designed to determine if there is any statistically significant evidence to the above problems.

While welding is a multifaceted and interdependent process, a narrower focus of the process is required within the confines of this research due to several limiting factors. As any one of the multitude of elements included in the process could be addressed singularly, or in different combinations, the following smaller set of identifiable questions was utilized to address possible conclusions.

The major questions to be addressed by this study are: 
1. Is there a definable level of variance in the tensile strength of a welded joint if the preparation angle is different from that of the industry standard?

2. At what range is the included preparation angle of a joint not statistically significant?

3. At what range is the included preparation angle of the joint statistically significant on the tensile strength of the joint?

The failure of welded joints in various structures and products can have disastrous consequences. Also, in the competitive global market, any costs that can be reduced while still maintaining the full integrity of the product would give a competitive advantage to manufacturers. In many cases this extensive analysis is neither practical nor economically feasible. In order to get products to market as fast as possible, welds are specified according to industry standards that have been proven over time, through experience. However, costs could be decreased by reducing the amount of preparation prior to welding that will still allow the weld to achieve the desired strength.

\section{Statement of the Hypothesis}

Null Hypothesis 1 . There is no statistically significant difference in the mean group values of the tensile strength of the sample population at the various preparation angles. Null Hypothesis 2. The industry standard of $60^{\circ}$ included preparation angle of single-vee butt joint will not yield the highest tensile strength.

\section{The Delimitations}

In order to create a balance between reasonable expectations and statistically significant research results, the following delimitations were used in this study:

1. The included angles to be tested were limited to less than $130^{\circ}$ because multiple weld passes would be required to fully fill the joint at any greater angle. 
2. Failure in the parent material, and not that of the weld joint, was considered to be at the yield strength of the parent material.

\section{The Limitations}

Due to the various limiting factors of time, money, and resources, the scope of this research was limited by the following characteristics:

1. Creation of the weld was limited to metal-inert gas (MIG) welding, and other welding processes may yield different results.

2. The welding parameters used were set according to the manufacturer of the welder's recommended settings for the given material and weld configuration.

3. Only a single pass weld was used since multiple passes would change the characteristics and properties of the welded joint.

4. Testing only occurred on carbon steel of ASTM A36 composition and other materials may yield different results.

5. Only a single-vee joint preparation style was used, and different preparation practices may achieve dissimilar results.

6. Although various testing methods are often used for test weld specimens, only tensile testing was used due to time and resource restrictions.

\section{The Assumptions}

In an effort to focus this research in the most efficient manner, the following assumptions were made in pursuit of this research:

1. The welding parameters specified by the manufacturer of the MIG welder meet or exceed industry standards. 
2. The automatic welding apparatus used produced consistent, repeatable welds with the same properties.

3. The welding wire used in the MIG welder was homogenous and had consistent composition.

4. The shielding gas used in the welding process meets or exceeds the minimum requirements for mixture and composition of 75\% Argon and 25\% Carbon Dioxide.

5. All steel purchased for use in testing will be of a consistent homogeneous nature and conform to all composition specifications of ASTM A36.

6. The structural composition of the pull test apparatus and testing load cell is square/flat/parallel to reduce the induction of non-axial forces in the planar testing.

7. Tensile testing load cell meets or exceeds calibration requirements as per ASTM E-4 specifications.

8. All software utilized is completely operable and free of defects that could affect the recording of data or the computation of test results.

9. Any changes in production or measuring environments had a negligible effect on the results of test samples.

10. All empirical data were captured manually by the researcher prior to computerized documentation, thus, any potential negligible errors in recording will not significantly result in the bias of statistical analysis.

\section{Terminology}

Arc Voltage. The voltage across the welding arc.

Automatic Welding. Welding with equipment which performs the entire welding operation without constant observation and adjustment of the controls by an operator. 
Bare electrode. A filler metal electrode, used in arc welding, consisting of metal wire with no coating other than that incidental to the drawing and storage of the wire.

Base metal (Parent metal). The metal to be welded.

Bead weld. A type of weld composed of one or more strings or beads deposited on an unbroken surface.

Bevel angle. The angle formed between the prepared edge of a member and a plane perpendicular to the surface of the member.

Blowhole. Void, hole, or cavity formed by trapped gas, dirt, grease, or any other foreign substance.

Butt joint. A joint between two members lying approximately in the same plane.

Butt weld. A weld in a butt joint.

Complete Joint penetration. Joint penetration which extends completely through the welded joint.

Crater. A depression at the termination of a weld bead.

Current regulator. An automatic electrical control device for maintaining a constant current in the primary of the welding transformer.

Deposited metal. Filler metal that has been added during a welding operation.

Deposition rate. The weight of metal deposited in a unit of time.

Depth of fusion. The distance that fusion extends into the base metal from the surface melted during welding.

Edge preparation. The contour prepared on the edge of a member for welding.

Face of weld. The exposed surface of a weld on the side from which welding was performed. 
Filler metal. Metal to be added in making a weld.

Flux. Fusible material or gas used in welding either to dissolve or prevent the formation of oxides, nitrides, or other contaminations.

Fusion. The melting together of filler metal and base metal, or of a base metal only, which results in coalescence.

Fusion zone. The area of base metal melted as determined on the cross section of a weld.

Gas pocket. A weld cavity caused by entrapped gas.

Heat-affected zone. That portion of the base metal which has not been melted, but whose mechanical properties or microstructures have been altered by the heat of welding or cutting.

Incomplete fusion. Fusion which is less than complete.

Joint geometry. The shape and dimensions of a joint in cross section prior to welding.

Joint penetration. The minimum depth a groove weld extends from its face into a joint, exclusive of reinforcement.

Joint. The location where two or more members are to be joined by welding.

Machine welding. Welding with equipment which performs the welding operation under the observation and control of an operator.

Manual welding. Welding wherein the entire welding operation in performed and controlled by hand.

Melting rate. The weight or length of electrode melted in a unit of time.

Partial joint penetration. Joint penetration which is less than complete.

Pass. A single longitudinal progression of a welding operation along a joint or weld deposit. The result of a pas is a weld bead.

Polarity. Direction of flow of current. 
Porosity. Presence of gas pockets or voids in metal.

Regulator. A device for controlling the delivery of gas at some substantially constant pressure regardless of variation in the higher pressure at the source.

Reinforcement of weld. Weld metal on the face of a groove weld in excess of the metal necessary for the specified weld size.

Single-vee groove weld. A type of groove weld in which only one edge has been prepared with a specified profile.

Spatter. The metal particles expelled during welding and which do not form part of the weld.

Square groove weld. A type of groove weld in which the edge to be welded is perpendicular to the surface of the base metal.

Underbead crack. A crack in the heat affected zone not extending to the surface of the base metal.

Undercut. A groove melted into the base metal adjacent to the toe of a weld and left unfilled by weld metal.

Voltage regulator. An automatic electrical control device for maintaining a constant voltage supply to the primary of a welding transformer.

Weld. A localized coalescence of metal wherein coalescence is produced by heating to suitable temperatures, with or without the application of pressure or filler metal.

Weld bead. A weld deposit resulting from a pass.

Weld metal. That portion of a weld which has been melted during welding. The portion may be either the filler metal or base metal, or both. 
Welded joint. A localized union of two or more members produced by the application of the welding process.

Weldment. An assembly whose component parts are joined by welding.

\section{Summary}

The goal of this investigation was to determine the effects of the preparation angle in a single-vee groove weld on the tensile strength of the joint. The industry standard for butt joints is to prepare a $60^{\circ}$ included angle on the material at the joint, depending on material thickness, in order to have the strongest weld joint possible. This research tested the effects of the joint preparation angle by increasing and decreasing the angle at the joint in $10^{\circ}$ increments of the included angle from the industry standard. A tensile tester was then used to test the samples and the results were then analyzed to find if there is a statistically significant difference in preparation angle from that of the industry standard. The material used throughout the test was ASTM A36 steel. In order to perform repeatable welds, the manufacturer's recommendations parameters for welding were used and a repeatable weld was achieved by machine welding. 


\section{Chapter 2}

\section{Review of literature}

Welding is by no means a new science. According to some researchers, its origin dates back to the very beginning of the technology of metals. Welding and its application have progressed slowly because of the limitations of the primitive methods used and the technical

knowledge available. Toward the end of the $19^{\text {th }}$ century and the beginning of the $20^{\text {th }}$ century, the art and science of welding began to advance at a very rapid pace because of technological advancements (Rossi, 1954).

Welding is "a process in which materials of the same fundamental type or class are brought together and caused to join (and become one) through the formation of primary (and, occasionally, secondary) chemical bonds under the combined action of heat and pressure" (Messler, 1993, p. 40). Heat can be provided by an electric arc, a gas flame, a chemical reaction, or the electrical resistance of the metals being joined to electrical current. Welding lends flexibility to machine designs and facilitates lightweight construction. (Oberg, Jones, Horton, \& Ryffel, 1992)

The key concept is that multiple entities are made one by establishing continuity, where continuity implies the absence of physical disruption on an atomic scale, but not homogeneity of chemical composition. Welding does not only apply to metals but also to other materials, such 
as certain polymers and glass, can also be welded even though the specific process may be called by a different name (American Welding Society, 1976).

\section{Structural Steel}

Structural steels are produced in forms of sheets, plate, bars, tubing, and structural shapes such as I-beams, wide-flange beams, channels, and angles. The American Society for Testing and Materials (ASTM) assigns a number designation to these steels, which is the number standard that defines the required minimum properties. "A very popular steel for structural applications is ASTM A36, a carbon steel used for many commercially available shapes, plates, and bars. It has a minimum yield point of $36 \mathrm{ksi}$, is weldable, and is used in bridges, buildings, and for general structural purposes" (Mott, Machine Elements in Mechanical Design, 2004, p. 54). Table 1 lists the mechanical properties of ASTM A36.

Table 1

Material Properties of ASTME A36 Steel (Mott, Applied Strength of Materials, 2006, p. 648).

\begin{tabular}{cccccc}
\hline $\begin{array}{c}\text { Material } \\
\text { ASTM } \\
\text { No. }\end{array}$ & \multicolumn{2}{c}{ Ultimate Strength, $s_{u}$} & \multicolumn{2}{c}{ Yield Strength, $s_{y}$} & Percent Elongation \\
\cline { 2 - 5 } & ksi & MPa & ksi & MPa & in 2 inches \\
\hline A36 & 58 & 400 & 36 & 248 & 21 \\
\hline
\end{tabular}

Generally, the more steel is worked, such as forging and machining, the stronger it will be. Some forms of steel, such as ASTM A36, are produced by hot rolling (HR) the steel while it is still at an elevated temperature. This produces a relatively soft, low strength steel which has high ductility and is easier to form. Cold rolling (CR) the steel while it is at, or near, room temperature produces a higher strength and lower ductility (Mott, 2006). 


\section{Fusion Welding Process}

In the fusion welding process, part edges are heated above the melting point of the material. This allows atoms from the substrates to be brought together in liquid state to establish material continuity and create large numbers of primary bonds across the joint after solidification. Sometimes, filler material must also be melted and added in order to completely fill the gap. Fusion welding processes include all processes in which the melting or fusion of portions of the substrates play a principal role in the formation of bonds to produce a weld (Messler R. W., 1999).

Although there are several different types of fusion welding, the primary focus of this research is on metal-inert gas, or MIG welding. MIG welding is a specific type of gas-metal arc welding (GMAW) which employs a continuous consumable solid wire electrode and an externally supplied inert shielding gas. Figure 1 displays the components used for MIG welding.

The consumable wire electrode produces an arc at the workpiece and provides filler metal to the weld joint. The externally supplied shielding gas protects the arc and molten metal from the oxidizing effect of the air and provides desired arc characteristics through its effect on ionization (Messler R. W., 1999). A schematic of the process is shown in Figure 2.

An advantage of MIG welding is that the mode of molten metal transfer from the consumable wire electrode can be changed and controlled through a combination of shielding gas composition, power source type, electrode type and form, arc current and voltage, and wire feed rate.

The different modes of metal transfer include spray, globular, and short-circuiting. The spray transfer mode is characterized by the transfer of small molten particles of droplets from the consumable electrode to the work. Globular transfer is characterized by large globules of molten 


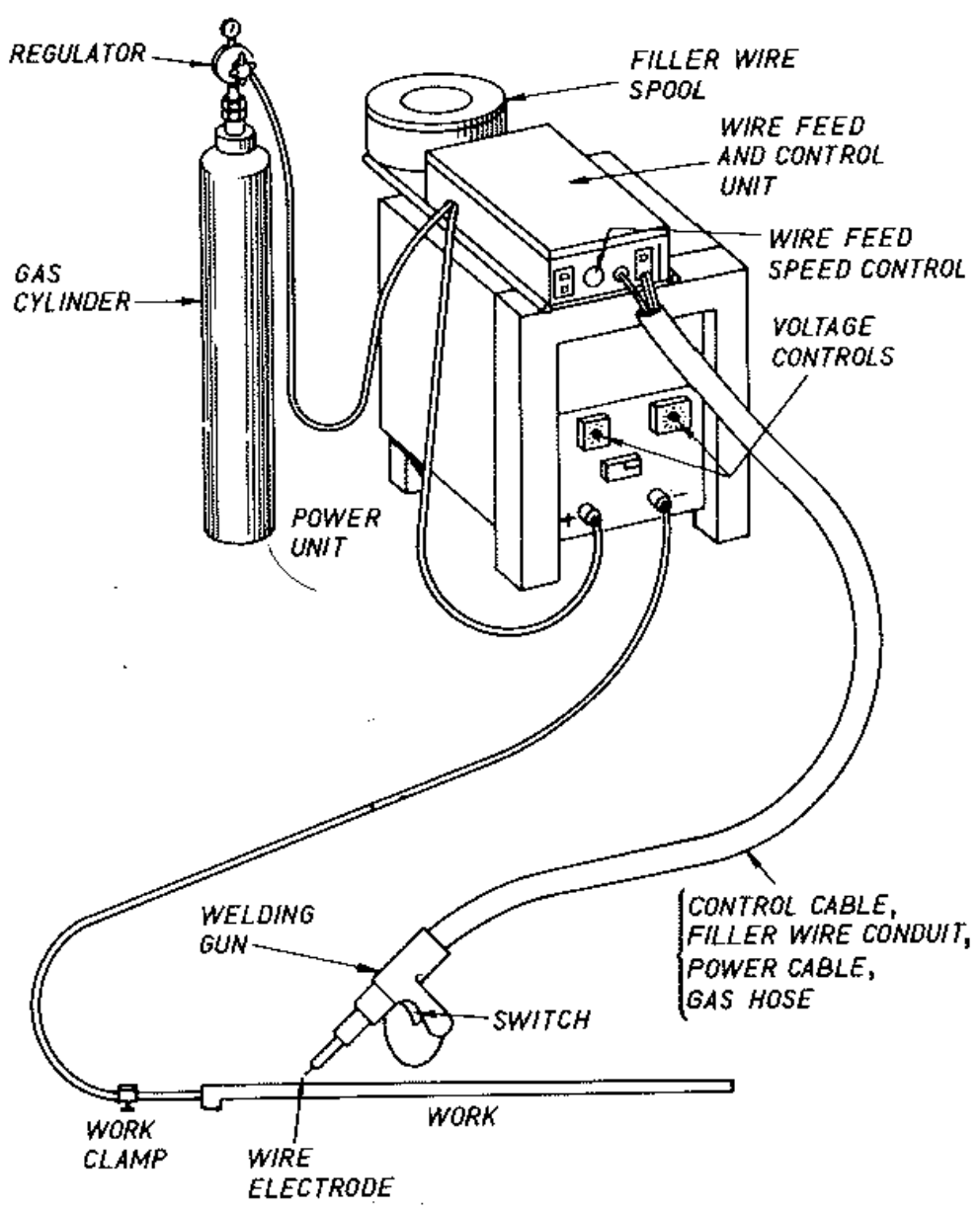

Figure 1. Components of the MIG welding process (Davies, The Science and Practice of Welding, 1984, p. 427).

metal that are formed at the tip of the electrode and are then transferred to the work piece. In the short-circuiting mode, slow forming molten globules at the end of the consumable electrode are periodically touched to the weld pool (Rossi, 1954).

\section{The Structures of the Welded Joint}

Four distinct microstructural zones will result in a welded joint from the welding process. The main zones include the fusion zone (FZ) or welded metal zone, the weld interface (WI), the heat affected zone (HAZ), and the unaffected base metal zone or parent metal zone (PM). Figure 3 shows the zones in relation to the joint. 


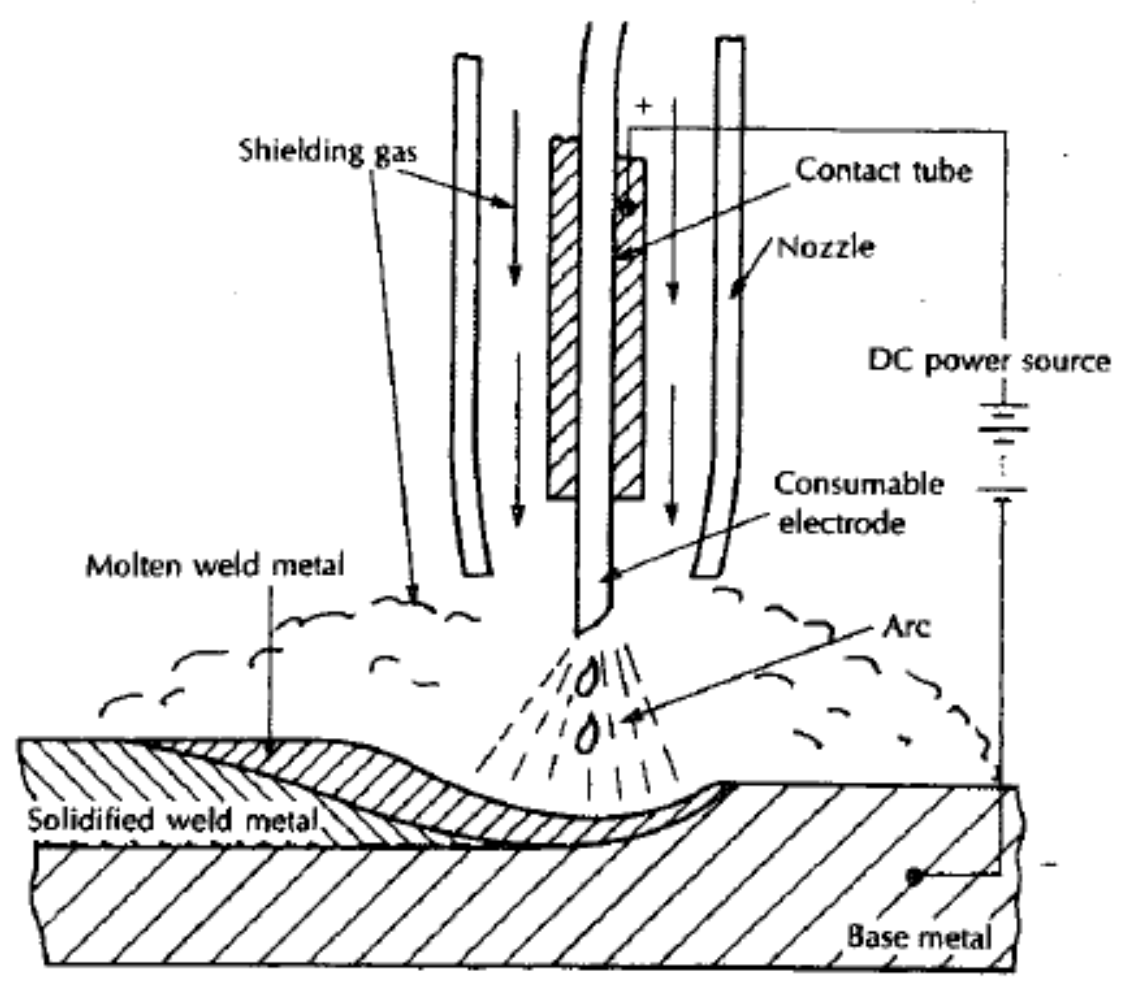

Figure 2. Schematic of the MIG welding process showing torch, weld, and electrical hookup (Messler R. W., 1999, p. 51).

The fusion zone is the portion of the weld that melted during welding by being heated to above the temperature where melting begins for the material being welded. It is composed of the parent metal and filler metal that were melted during the welding process to form a relatively homogeneous structure (Messler R. W., 1999). The weld interface zone, also known as the fusion line, is located between the fusion zone and the heat affected zone. Only partial melting takes place in this narrow boundary, which results in a mixture of grain structures (Farhat, 2007).

The HAZ lies outside the fusion zone and is the region affected by the heat of the welding. The temperature of the material in this zone rises high enough to change the microstructure, but below the melting point of the material. Changes in the structure in the HAZ 


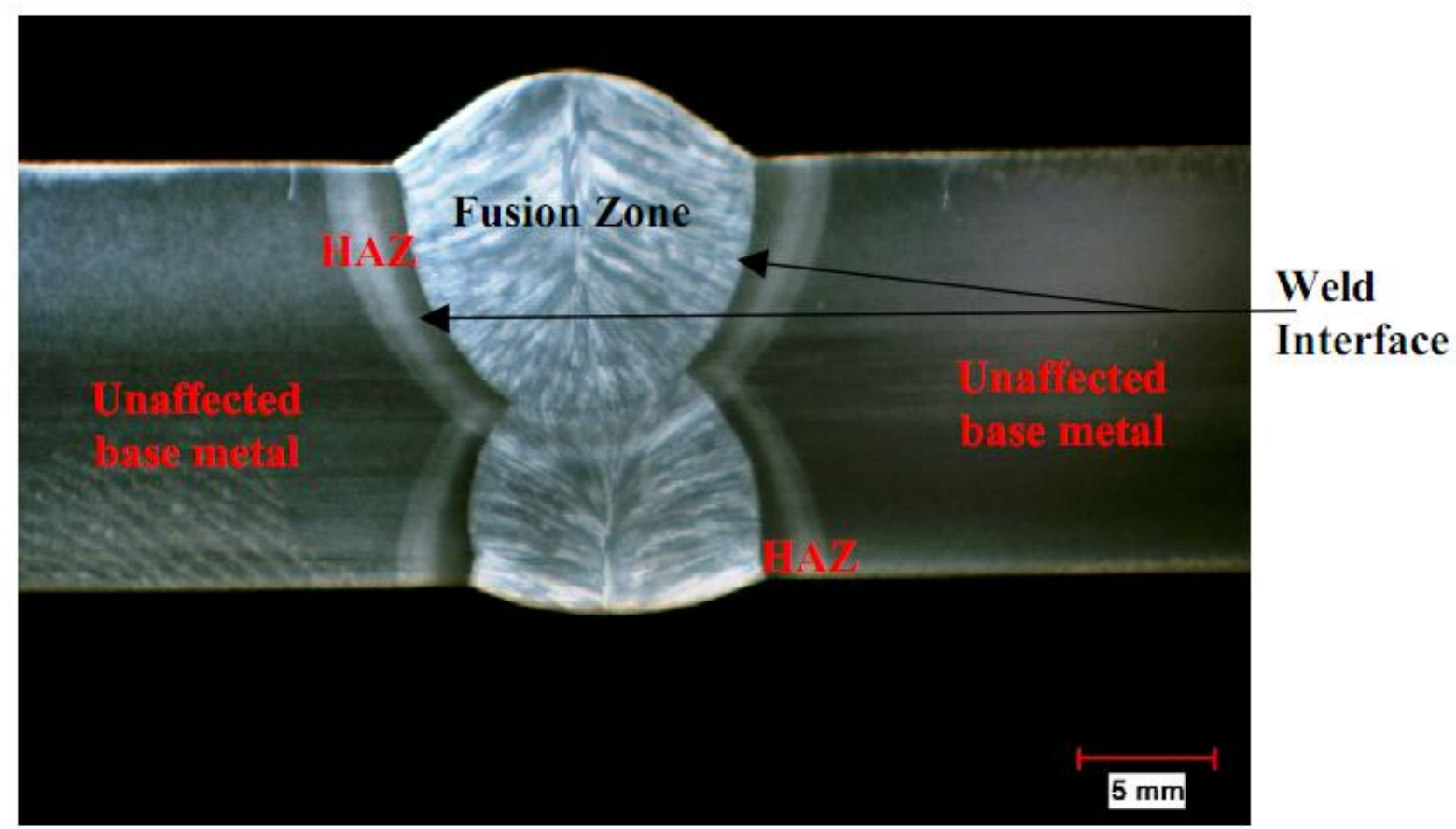

Figure 3. Structure of a welded joint (Farhat, 2007, p. 8).

result in changes in properties. It is an undesirable region because it is characterized by high brittleness due to its coarse grain structure which allows for easy crack propagation and is the area where failures usually occur (Messler R. W., 1999).

MIG Welding Parameters

The deposition rate, bead shape, and properties of the welded joint are controlled by the welding parameters. The parameters include the welding wire chemistry, wire size and extension, heat input, current, voltage, speed, and shielding gas.

\section{Welding wire.}

Filler wire is commonly supplied on reels that are available in various diameters and varying capacities of wires. The bare steel wire is often coated in copper to improve 
conductivity, reduce friction at high feed speeds, and to minimize corrosion while in stock (Davies, The Science and Practice of Welding, 1984).

\section{Wire size.}

Wire used in MIG welding is available in differing diameters. Wire size affects the deposition rate, with a smaller diameter wire usually able to carry a larger current rate and deposition rate than a larger wire at the same current. Large diameter wires have high current capacities and can carry more current and produce higher deposition rates than smaller diameter wire at the same current. Selection of wire size is also dependent on feed rate. When all conditions are kept constant except for wire size, an increase in the wire size will increase the bead width and decrease the penetration and deposition rate (Farhat, 2007).

\section{Wire extension (stickout).}

The current necessary to create an arc reaches the wire at the contact tube within the nozzle of the welding gun. To reach the arc, the current travels a distance from the contact tube to the tip of the wire. This distance is known as the wire stickout, or wire extension, and it adds resistance as the current passes through it. The longer the wire extension, the greater the heat builds up within it. This causes a voltage drop that occurs between the contact tip and the arc, which reduces the penetration (Farhat, 2007).

\section{Welding speed.}

Also known as travel speed, welding speed affects the quality and properties of a weld. It can be used to control bead size and penetration. Excessive speed can cause a lack of penetration, a lack of fusion, porosity, and an uneven bead shape. Slow speed can result in excessive arc exposures and high heat input that produces a large HAZ (Farhat, 2007). 


\section{Welding voltage.}

Welding voltage, which controls the arc length, has an important effect on the type of metal transfer desired. "Short arc welding requires relatively low voltages while spray arc requires higher voltages... [As] welding current and wire burnoff are increased, the welding voltage must also be increased somewhat to maintain stability" (ESAB North America, 2010). The voltage setting directly controls the arc length. A certain range is necessary to maintain arc stability at any welding current level.

\section{Welding current.}

The welding current is the electrical amperage in the power system as the weld is being made and determines the rate at which the wire is melted, the amount of parent metal melted, and the depth of penetration (Rossi, 1954). In the MIG welding process, "welding current is directly related to wire-feed speed. As the wire-speed is varied, the welding current will vary in the same direction" (ESAB North America, 2010). If there is an increase, or decrease, in the wire feed rate it will cause an increase, or decrease, in the current.

\section{Shielding gasses.}

To avoid contamination various gasses and combinations of gasses are used to shield the weld. Argon and helium are inert gasses that are used, and carbon dioxide is also used. Air in the weld zone is displaced by shielding gas in order to prevent contamination.

Contamination is caused mainly by nitrogen, oxygen and water vapor present in the atmosphere... Nitrogen in solidified steel reduces the ductility and impact strength of the weld and can cause cracking. In large amounts, nitrogen can also cause weld porosity. Excess oxygen in steel combines with carbon to form carbon monoxide $(\mathrm{CO}) \ldots$ causing porosity... When hydrogen, present in water vapor and oil, combines with... iron..., 
porosity will result and 'underbead' weld metal cracking may occur. (ESAB North America, 2010)

The basic properties of the shielding gasses that affect the performance of the weld are: "Thermal properties at elevated temperatures; Chemical reaction of the gas with the various elements in the base plate and welding wire; Effect of each gas on the mode of metal transfer" (ESAB North America, 2010). The thermal conductivity of the gas at arc temperatures affects the arc voltage required, as well as the temperature delivered to the weld. The selected gas must also be compatible with the wire and base metal. Shielding gasses also affect the depth that the work piece is melted and the mode of metal transfer.

\section{Weld Joint}

The size and the shape of the weld joint will influence how the heat is deposited by the source of energy and how it flows and distributes in the weld. The loads in a welded structure are transferred from one member to another through the welds placed at the joints. The type of joint is often determined by the requirements and restrictions of the structure and the type of load. Other factors include the accessibility to the joint for welding and inspection, the welding

process required, and cost constraints (Messler R. W., 1999). See Figure 4 for some typical weld joint configurations.

Butt joints, or welds, are also called square butts or straight butts when they are produced from base material that has been prepared before welding with square edges. Such joints do not require filler metal if they fit together tightly. Butt joints can also have other preparations that require filler metal. These joints include single or double-vee, single or double bevel, single or double $\mathrm{J}$, or single or double U. 
Square-groove joints are simple to prepare, economical to use, and provides satisfactory strength, but is limited by joint thickness. For thick joints, the edge of each member of the joint must be prepared to a particular geometry to provide accessibility for welding and to ensure the desired weld soundness and strength... The opening or gap at the root of the joint and the included angle of the groove should be selected to require the least weld metal necessary to give needed access and meet strength requirements. (Messler R. W., 1999)

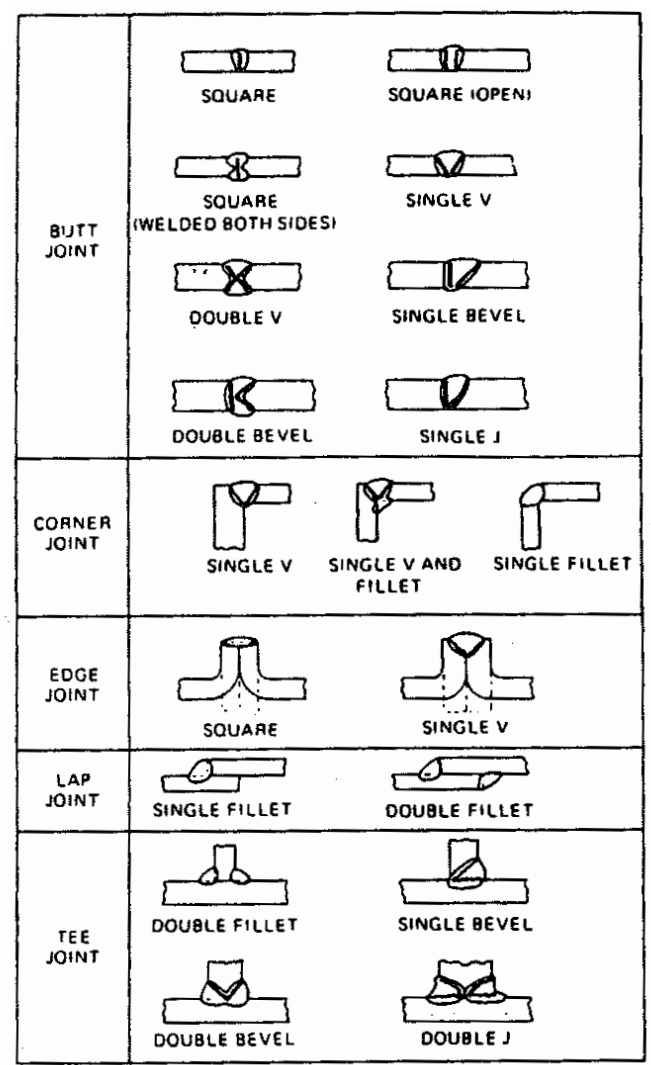

Figure 4. Typical weld joint variations. (Messler R. W., 1999, p. 151)

If the material is too thick for the selected welding process to get full penetration, then the joint must be prepared with the desired geometry so that the weld will have full strength. "Single-groove joints... with complete penetration, are capable of developing the full strength of 
the base metal, regardless of the type of loading which they undergo in service" (Rossi, 1954, p. 552). The type of edge preparation chosen is based on the intensity of loading and its characteristics, the effects of warping during cooling, and the cost of the joint preparation.

The joint type of this research is the single-vee groove joint, which applies to butt and corner joints. "Single-vee groove joints are economical from the standpoint of welding required, when depth of chamfering is between one-quarter and three-quarters of an inch. In general, the single-vee groove joints are for most loading conditions and are used with plate thicknesses considerably greater than the square-groove joints, but their use on thinner sections is not unusual" (Rossi, 1954). The preparation of the angle costs more than that of the square-groove method and more filler material is required, but it helps ensure full penetration and joint strength. The proportions of a single-vee preparation of a weld joint can be found in Figure 5, while Figure 6 and Figure 7 give examples of incomplete weld penetration and complete weld penetration, respectively.

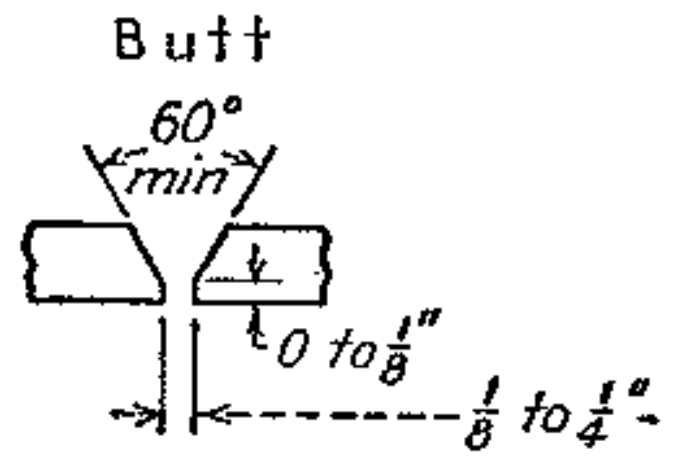

Figure 5. Proportions for a single-V groove joint. (Rossi, 1954, p. 555)

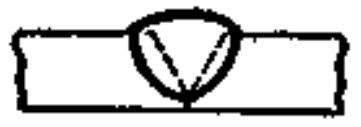

Figure 6. Incomplete penetration of a welded single-V butt joint. (Rossi, 1954, p. 555) 


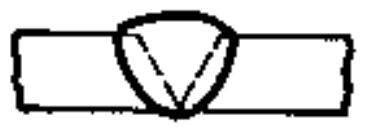

Figure 7. Full penetration of a welded single-V butt joint. (Rossi, 1954, p. 555)

Regardless of the type of joint or any joint preparation, "joint edges should be carefully prepared and free from scale, paint, rust and oil, etc. and butt seams should fit tightly together" (Davies, The Science and Practice of welding, 1977, p. 492). This eliminates possible contaminates that may affect the properties of the weld. If the welded joint were contaminated it could affect the tensile strength of the sample.

\section{Weld Failure Analysis and Prevention}

During the welding process various types of defects and faults may occur. Tests have been developed in order to determine weld quality and strength.

Weld testing may either be destructive or nondestructive in nature. The destructive tests supply quantitative information. The nondestructive tests are indicative of quality alone... and some of them are indicative only to a limited extent. Welding authorities are usually in full agreement on the quality and properties to be determined in a weldment and on the inspection and test methods in general, but all too often the differ widely in the shape and size of the test specimens and on the details of the test procedures. (Rossi, 1954, p. 645)

There are various tests that are specified for different weld configurations and material.

\section{Nondestructive tests.}

Nondestructive tests, as the name implies, do not affect the sample and are done in order to determine if there are any apparent defects in the weld. 
Visual inspection is one of the most widely used inspection methods and is used to help determine the adequacy of the weld for its intended use.

Careful examination of what can be seen on the surface of a welded joint can be of great help in determining the ultimate acceptability of the structure, especially when used in conjunction with other processes... In order to obtain the best picture of the quality of the weldment, visual examination must be synchronized with welding operations. Thus, the structure to be welded should be examined prior to welding, during welding, and after welding. (Rossi, 1954, p. 664)

Inspecting the work piece prior to welding indicates whether the material contains flaws such as delamination and blisters. It also shows whether the weld area is clean of contamination. Inspecting the joint during welding will indicate that the proper settings are being used for the required weld. Visual inspection after welding may indicate possible flaws in the joint, such as cracking, porosity, dimensional accuracy, and continuity of the weld (Rossi, 1954).

Magnetic-particle inspection can be used to locate surface defects and defects that are near the surface.

With magnetic particle inspection, a magnetic field is induced in the piece, by means of high-amperage electrical currents, so that expected defects will be cut by that field. Where the discontinuity interrupts the magnetic field in the piece, a leakage field results on the surface, and when finely divided magnetic particles are blown over the surface or flowed on the surface in liquid suspension, the magnetic particles are held by the leakage field at the crack to build up a visible indication of the defect. (Rossi, 1954, p. 666) This method is only applicable on ferromagnetic metal and cannot be used to inspect nonferrous metals such as aluminum or stainless steel. 
Fluorescent-penetrant inspection is used for locating any defects on the surface of the weld or parent material and is often used on nonmagnetic metals.

In fluorescent-penetrant testing, penetrant is applied to the surface to be inspected by dipping, spraying, or brushing, and a period of time from five minutes upward is allowed for the oil-based penetrant to enter any small surface opening through capillary action. Excess penetrant is removed from the surface, usually by water spray wash. The surface is dried in production driers, by air blast, or by simply standing in air, and a dry or wet developer is applied ultimately to form a film of dry powder over the surface to act as 'blotter' and to draw the fluorescent penetrant back from the defects. (Rossi, 1954, p. 669)

After processing, the surfaces are viewed with special lighting that the penetrant will fluoresce under which reveals surface defects suck as cracks and porosity (Rossi, 1954).

X-ray testing is recognized as one of the foremost nondestructive tests and has a wide industrial use.

Cracks, slag, blowholes, lack of fusion, and so on can readily be detected by X-raying the weldment. In general, the testing procedure constitutes placing the X-ray tube on one side of the piece being tested and the film on the other. The time of exposure may range from a fraction of a minute to several minutes, depending on the power of the tube and the thickness of the metal. (Rossi, 1954, p. 671)

The film is then developed and inspected for defects in the weld and surrounding areas.

\section{Destructive tests.}

Destructive tests may involve destruction of a complete sample, or that specimens called coupons, be cut from a larger piece to be tested. 
Tensile testing is done on a tensile testing machine capable of exceeding the yield point of the material in question. It is done by:

causing the welded specimen to fail by applying a measured load... During a tensile test, other factors besides tensile strength may be measured, such as yield point, elongation, and reduction of area. The yield point is reached when the metal continues to stretch without further increase in the applied load. The elongation figure is of little value, especially when the test of the weld metal, in such cases, is best obtained by means of a free bend test (Rossi, 1954, p. 647).

Tensile testing of flat specimens have been standardized by the American Society for Testing Materials (ASTM) and is shown in Figure 8 and Figure 9.

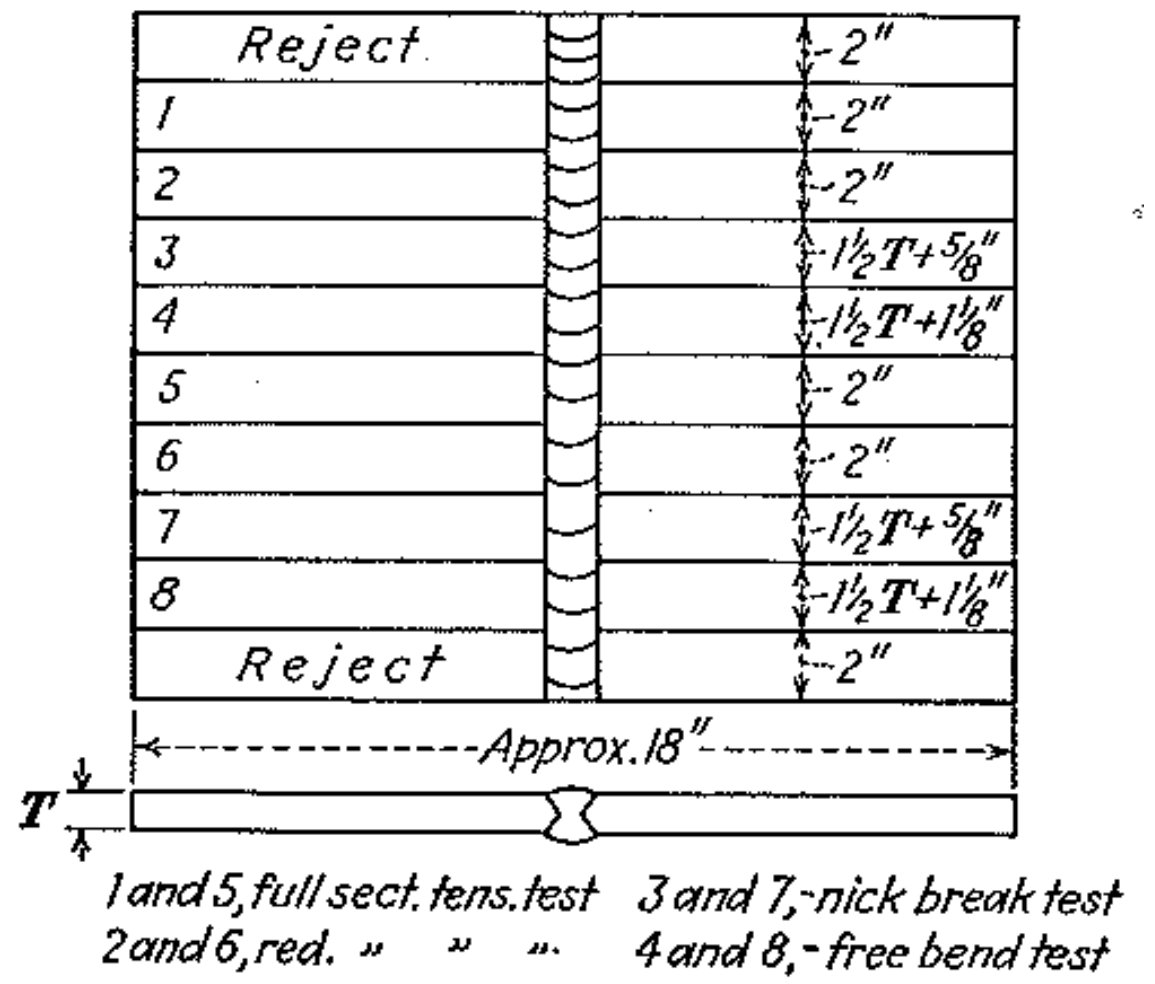

Figure 8. Typical required division of a test plate and the locations of the test specimens (Rossi, 1954, p. 647). 


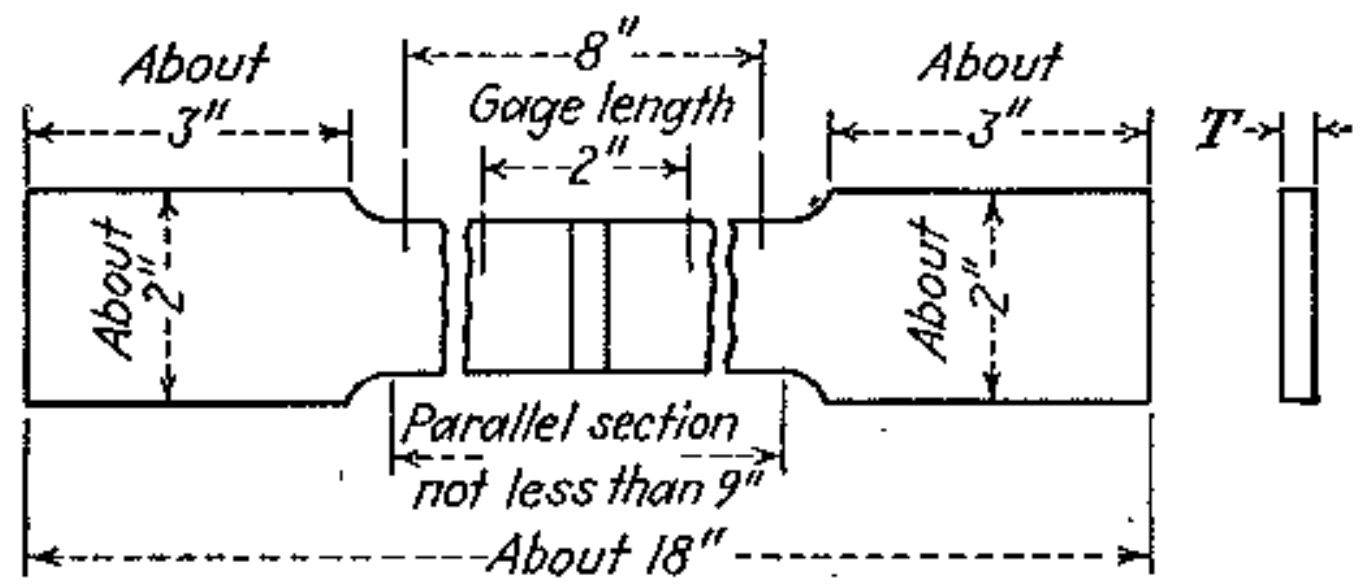

Figure 9. Full section tensile test specimens (Rossi, 1954, p. 647).

Tensile testing of a welded joint is not the same as doing the same test on a homogeneous bar . Tensile testing of welds is more complex than for base metal because, "the weld test section is heterogeneous in nature, composed of the deposited weld metal, the heat-affected zone, and the unaffected base metal. To obtain an accurate assessment of the strength and ductility of welds, several different specimens may be used" (American Welding Society, 1976, p. 157). Each zone of the welded joint may have a different grain structure and strength than the surrounding zones. The lack of uniform properties is particularly important because:

Straining and failure will tend to occur primarily in the weaker areas of the gage section. For example, if the weld metal strength exceeds that of the base metal, most of the plastic strain occurs in the base metal, with resultant necking and failure outside of the weld area. In such a case, the test indicates that the weld strength is above the ultimate tensile strength achieved in the specimen but does not give any indication of the weld ductility. (American Welding Society, 1976, p. 158) 
When the weld strength is lower than that of the parent material, the most strain occurs in the weld. This will result in fracture at the welded joint and little elongation. The primary information gained from this type of test is:

ultimate tensile strength; yield strength and elongation requirements are generally not specified. In spite of these deficiencies, the [tensile] weld test is the standard accepted ASME test for procedure qualification and is also quite widely used for the same purpose in various codes, since it does indicate whether or not the weld strength equals the base metal tensile strength or some other specified minimum value. (American Welding Society, 1976, p. 159)

The result of tensile testing gives the tensile strength of the bar itself and indicates a proper weld, but it does not indicate other conditions. The details of specimen preparation and test procedures for tensile testing can be found in Standard Methods for Mechanical Testing of Welds, AWS B4.0 and Standard Methods of Tension Testing of Metallic Materials, ASTM E8.

The free-bend test is used to "determine the ductility of the welded joint. The test yields quantitative data independent of the thickness and width of the specimen, provided that the width is not less than one and one-half times the thickness" (Rossi, 1954, pp. 651-652). Figure 10 shows the proper way to create a sample for a free-bend test.

After preliminary bends are made (see Figure 11) the specimen is placed in a vice or press and bent until failure occurs on the outside surface between the gauge marks. If no cracks or depressions appear, the specimen is then bent double. 


\section{Testing and Inspection}

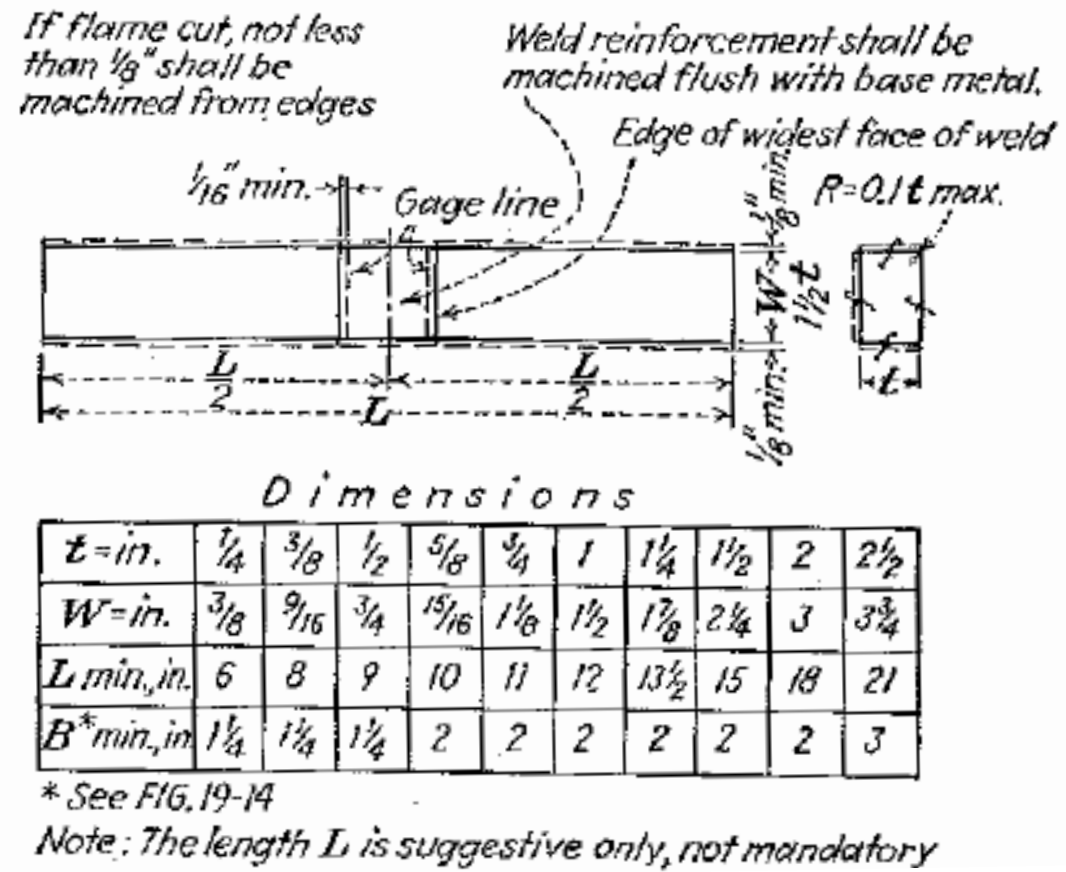

Figure 10. Free-bend test specimen in a plate (Rossi, 1954, p. 652).

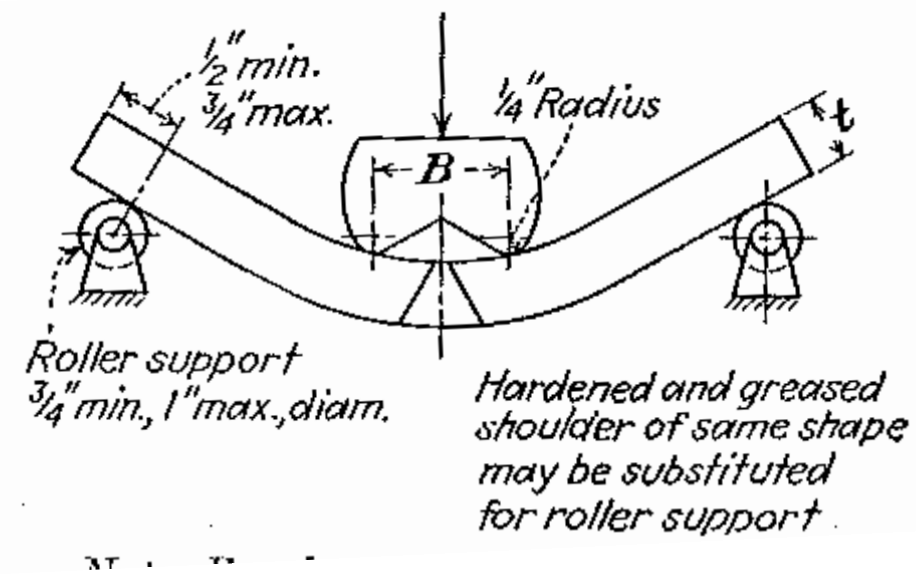

Figure 11. Method for initial bend for free-bend test specimens (Rossi, 1954). 
The hardness of a welded joint is affect by several factors and it is often desirable to limit the extent of the hardness in a weld.

There are numerous methods of measuring hardness... the Brinell, Rockwell, and Vickers hardness-measurement methods... are the three most widely used methods.. [and] consist of making a depression in the material under fixed conditions of load and indenter shape. The depth or area of the depression made becomes a measure of the hardness. (Rossi, 1954, p. 658)

The Brinell hardness test is done by mounting the specimen on an anvil and applying a pressure of a certain magnitude against a hardened-steel ball $10 \mathrm{~mm}$ in diameter in contact with the specimen. After a specific amount of time, the pressure is then released and the diameter of the indentation in the specimen is measured. The Rockwell hardness test is similar to the Brinell test, but measures the depth of the residual penetration made by a small hardened-steel ball or diamond cone (Davies, The Science and Practice of Welding, 1984).

\section{Summary}

Welding is not a new science and its origins date back to the very beginning of the technology of metals. Welding is a process in which materials are brought together and joined. The key concept is the multiple entities are made one by establishing continuity.

Although there are several different types of fusion welding, the primary focus of this research is on metal-inert gas, or MIG welding. MIG welding is a specific type of gas-metal arc welding (GMAW) which employs a continuous consumable solid wire electrode and an externally supplied inert shielding gas. The deposition rate, bead shape, and properties of the welded joint are controlled by the welding parameters. Wire size affects the deposition rate and the welding speed affects the quality and properties of a weld. Welding voltage, which controls 
the arc length, has an important effect on the type of metal transfer desired and the welding current is the electrical amperage in the power system as the weld is being made and determines the rate at which the wire is melted, the amount of parent metal melted, and the depth of penetration.

During the welding process various types of defects and faults may occur. Tests have been developed in order to determine weld quality and strength. Nondestructive tests do not affect the sample and are done in order to determine if there are any apparent defects in the weld. Destructive tests may involve destruction of a complete sample or that test specimens, called coupons, be cut from a larger piece to be tested.

There are several destructive and nondestructive tests that were not covered in this research, and few tests will be utilized during testing. The tests that will be used will help ensure material consistency prior to testing, during the welding process, and testing prior to welding. The main test utilized will be the tensile test, which will be used to compare the tensile strength of the welded joint. The researcher was unable to find any prior research where the variable in question, the preparation angle of the welded joint, was tested. 


\section{Chapter 3}

\section{Research Procedures}

MIG welding of single-vee groove butt joints is a process that requires the simultaneous function of several interdependent elements; the scope of this study centers on a single variable within this process. The variance is the mechanical performance associated to the weldment's tensile strength and its relationship to the preparation angle of the single-vee groove butt joint. For this study, it was imperative to capture empirical data of the tensile strength of the weld joint for assessment of the variation in mechanical pull resistance to the preparation angle.

Preparation angles were machined in ASTM A36 carbon steel, which were then machine welded together. Coupons were then plasma cut from the welded pieces and machined so a constant cross section was obtained. This yielded ten coupons per preparation angle and a total population of 130. The test samples were inserted into a United Testing Systems tensile tester (Figure12) to induce material failure and capture datum readings related to the amount of force required to induce the failure of either the weld, or base metal. 


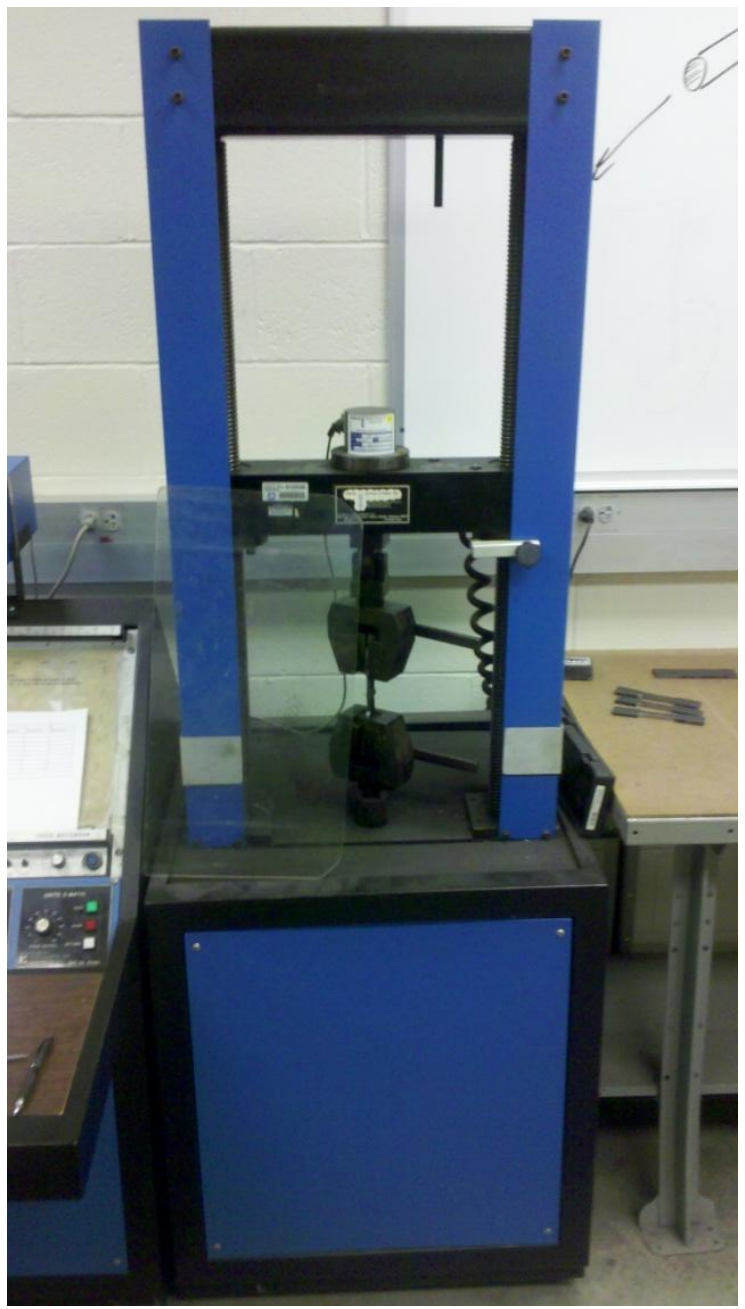

Figure 12. United Testing Systems tensile tester.

The data were inserted into SPSS 18 statistical software and recoded into banded groups to analyze the potential variance between groups, as well as to assess any possible correlation between the data values of the different preparation angles. A 95\% confidence interval was used.

This chapter will restate the major research questions, delineate the specific characteristics of the design, materials, manufacturing, and testing of the population of preparation angles, and describe the methodology of statistical analysis utilized to form conclusions about the stated hypothesis. 


\section{Restatement of the Research Question}

The major research questions of this study are:

1. Is there a definable level of variance in the tensile strength of a welded joint if the preparation angle is different from that of the industry standard?

2. At what range is the included preparation angle of a joint not statistically significant?

3. At what range is the included preparation angle of the joint statistically significant?

\section{Restatement of the Hypothesis}

The following hypothesizes were analyzed to determine if there were any statistically significant findings associated with this study:

Null Hypothesis 1. There is no statistically significant difference in the mean group values of the tensile strength of the sample population at the various preparation angles.

Null Hypothesis 2 . The industry standard of $60^{\circ}$ included preparation angle of single-vee butt joints will not yield the highest tensile strength.

\section{Methodology}

Upon commencement of designing the production and testing of this research, it was imperative to define the types and sources of the basic tooling, equipment, procedures, and raw materials to utilize within the confines of this study. In order to align this research with typical circumstances often found in real world applications, the commonly used weld joint of singlevee groove butt joint and ASTM A36 steel were chosen. Discussion with experienced professionals identified this combination as typically utilized in many design applications found in manufacturing and construction.

The first phase of the research was to specify the basic tooling and equipment for the production of the weld joint while striking a balance between normal production methods and the 
confines of limiting test factors. Specifically, a key element of the resultant pull force required to exceed the yield strength of the material is directly related to the cross sectional area of the specimen. To resolve this issue, additional machining steps were required to obtain consistent cross sectional area of the weld joint and base metal to be tested, often called necking or dogboning. The final production machining cycle methods chosen were to create preparation angle, weld the joints, cut into coupons, machine the coupons to consistent dimensions, and pull test them. In addition, to assure dimensional conformity of the final coupons, dimensional checking protocols were implemented by the researcher to inspect the dimensional accuracy of the samples throughout the processes using standard micrometers, calipers, and sine gauges. This was instituted to identify any conditions of warpage or machining imperfections that may alter the results.

Several pieces of manufacturing equipment and processes were required in order to complete the research, including: vertical milling machines, MIG welder, automated plasma cutting table, grinder, computer numerical control machining center, and tensile testing equipment. The researcher was trained in the use of the required equipment, and the safety concerns involved. Before creating the samples to be used in testing, an initial sample was run through the entire method to ensure that the planned methodology was sound.

\section{Initial machining procedures.}

Six pieces of ASTM A36 steel of the same production lot were obtained from a local supplier. The stock material was available in the required thickness $(0.25$ inches) and width (3 inches), but it was only available in 5 feet lengths. The stock ASTM A36 was cut into 12 inch

length sections using a shear (see Figure 13) to obtain the required initial dimensions as seen in 
Figure 14. A stop was used to obtain consistent and repeatable length of the samples (see Figure

15). Dimensional accuracy was tested at random points to ensure material uniformity.

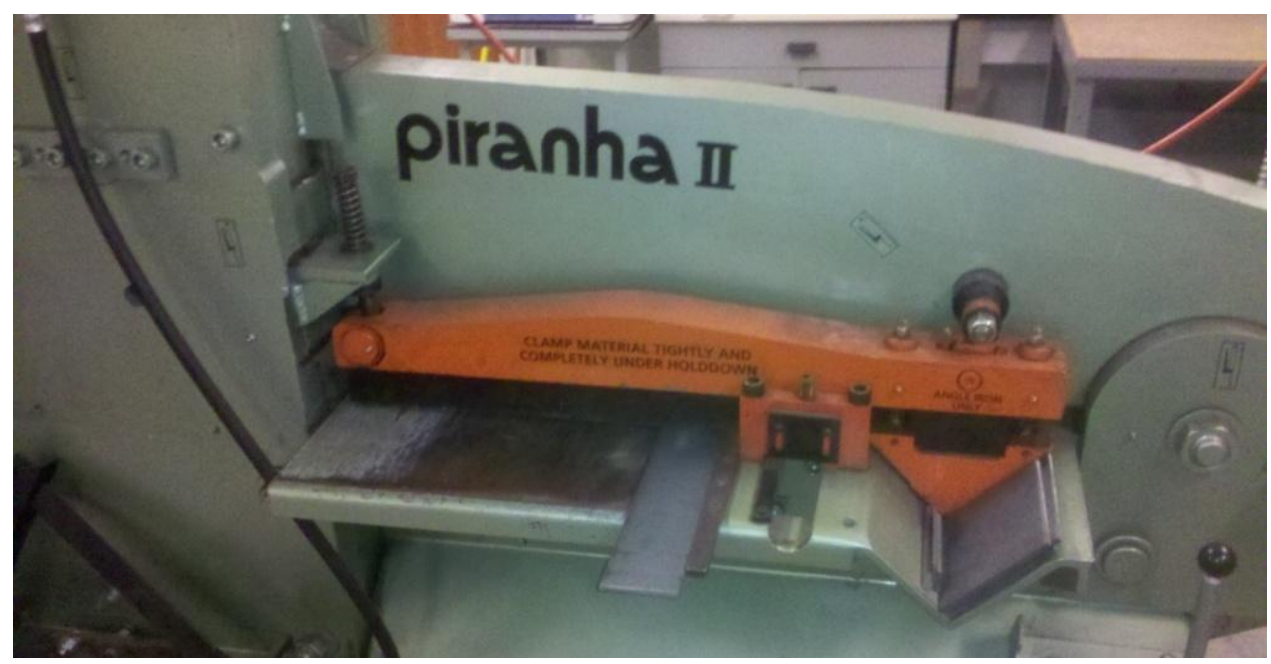

Figure 13. Stock material being sheared to required dimensions.
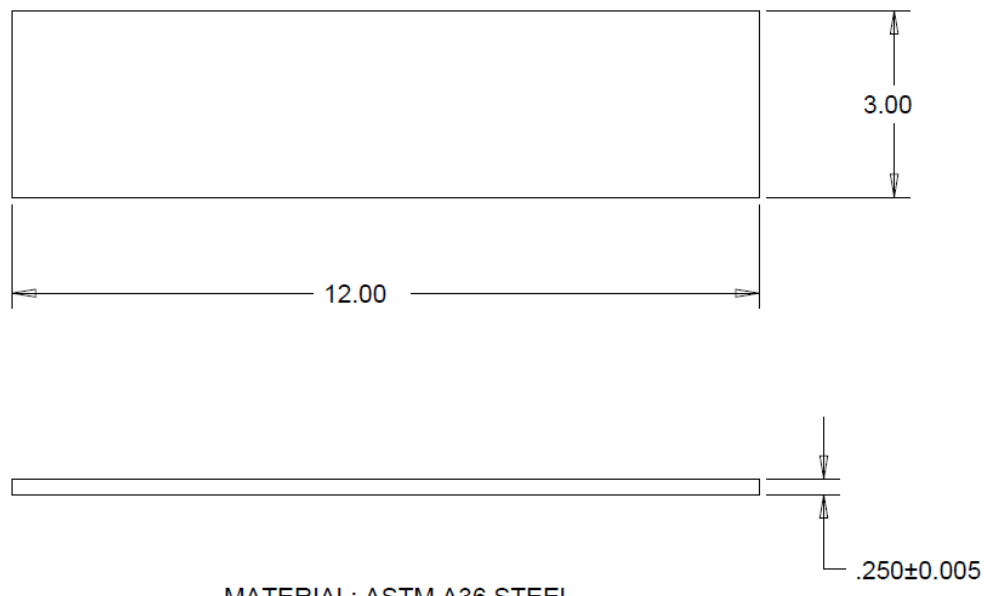

MATERIAL: ASTM A36 STEEL

UNITS IN INCHES

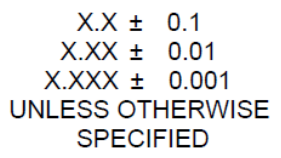

Figure 14. Dimensions of stock material for machining and testing. Dimensions are in inches. 


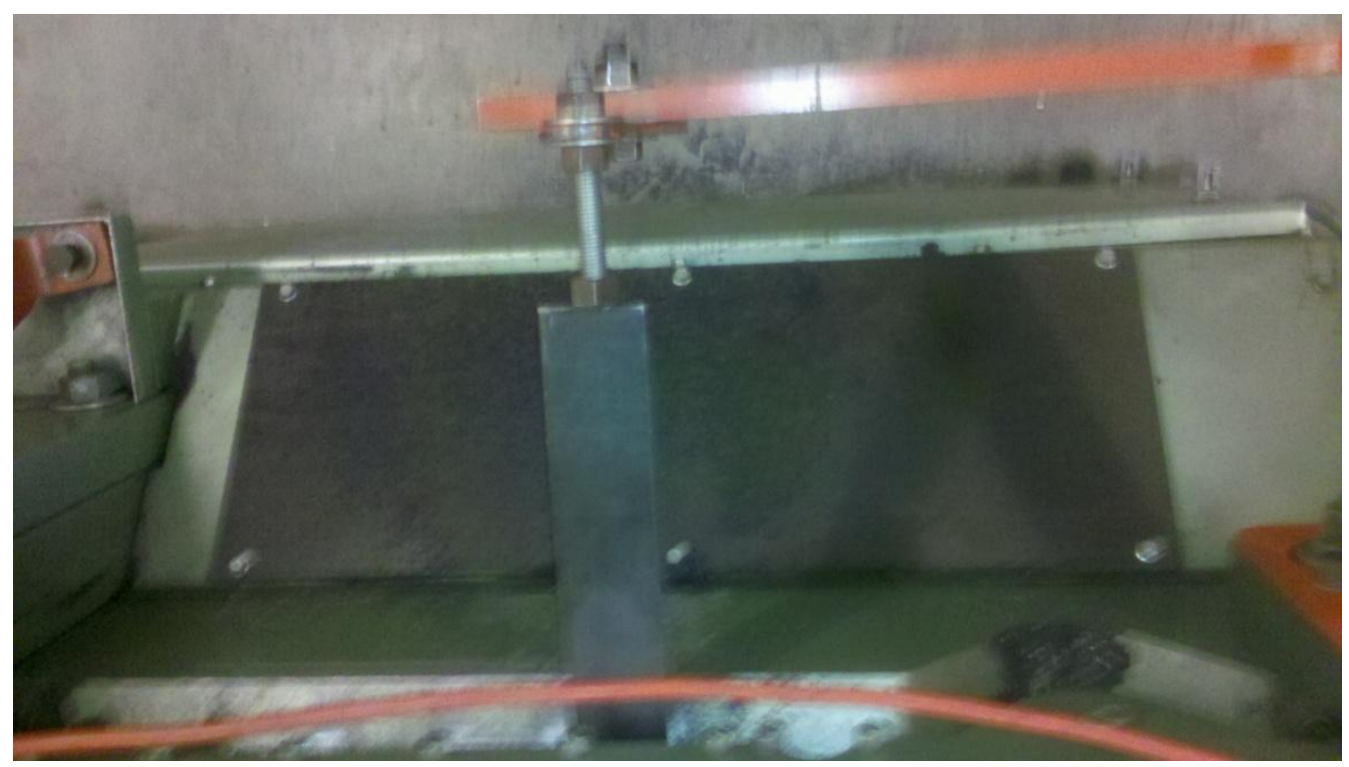

Figure 15. Stop used during shearing process to control length of samples.

A horizontal milling machine with required fixture was set up in order to machine the necessary preparation angles on each sample. However, when machining the initial sample it was found that the required clamps needed to securely hold the sample would interfere with the cutter head when at greater angles (see Figure 16).

After consulting with machining experts, it was determined that the best way of machining the preparation angles was to use a vertical milling machine with an angle vice in order to create angles in $5^{\circ}$ increments along the length of the sample (see Figure 17). 


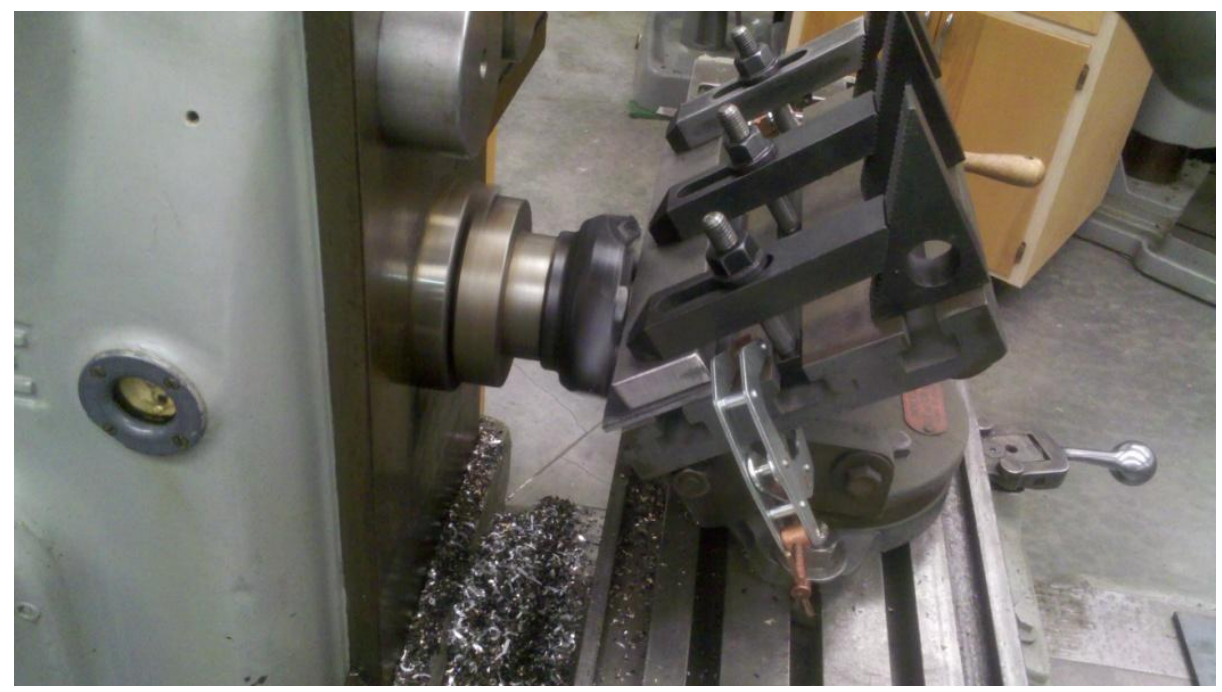

Figure 16. Machining of initial sample at $60^{\circ}$ included preparation angle. When angles increased, the clamps used to securely hold sample interfered with machining.

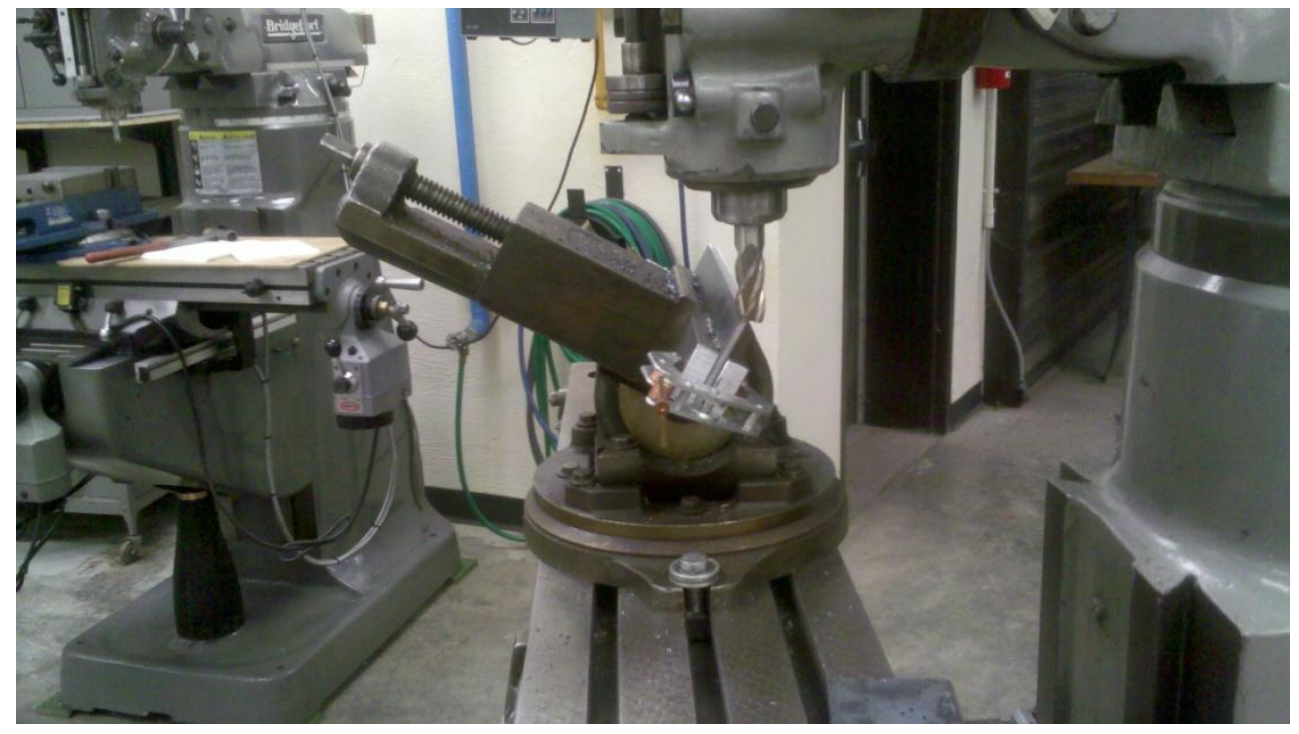

Figure 17. Milling of preparation angles. 
For proper machining, calculations were made in order to determine the proper settings. The following equation was used to determine the revolutions per minute (RPM) of the spindle, or the spindle speed.

$\mathrm{N}=12 \mathrm{~V} / \pi \mathrm{D}$

Where $\mathrm{N}=$ spindle speed $(\mathrm{RPM})$

$\mathrm{V}=$ cutting speed $=120$ feet per minute (Oberg, Jones, Horton, \& Ryffel, 1992)

$\mathrm{D}=$ diameter of cutter $=0.75$ inches

$\pi=3.1416$

Therefore $\mathrm{N}=12 * 120 \mathrm{fpm} / 3.1416 * 0.75$ in $=586 \mathrm{RPM}$

For machining, a four flute, 0.75 inch diameter, double-ended, high speed steel end mill was used in a Bridgeport vertical milling machine set at approximately 590 RPM. Since a different amount of material was removed at each angle, the feed rate was varied by the researcher on each pass in an attempt to reduce tool wear and chatter. Lubricant was used to reduce tool wear and assist in chip removal.

Along with the Vernier markings on the vice, a Vernier angle meter was used to further ensure the accuracy of the angles (see Figure 18).

\section{Welding procedures.}

Although a mechanical or automated welder would be ideal for this process, the researcher was unable to utilize one in order to conduct the research. To obtain a consistent weld profile, a Hobart Beta-MIG 200 welder was attached to a CSX Shape Cutter with Edge control center plasma cutting table in order to control the welding parameters. Figure 19 displays the equipment that was used during this procedure. 


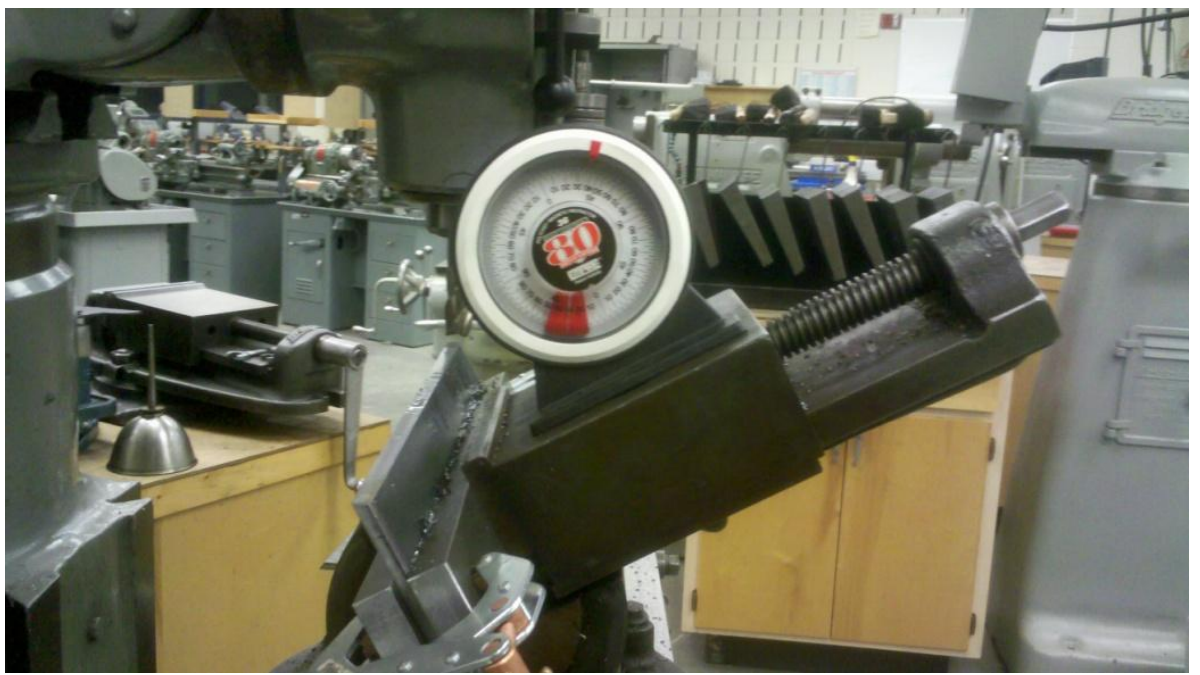

Figure 18. Vernier angle meter used to further ensure preparation angle accuracy.

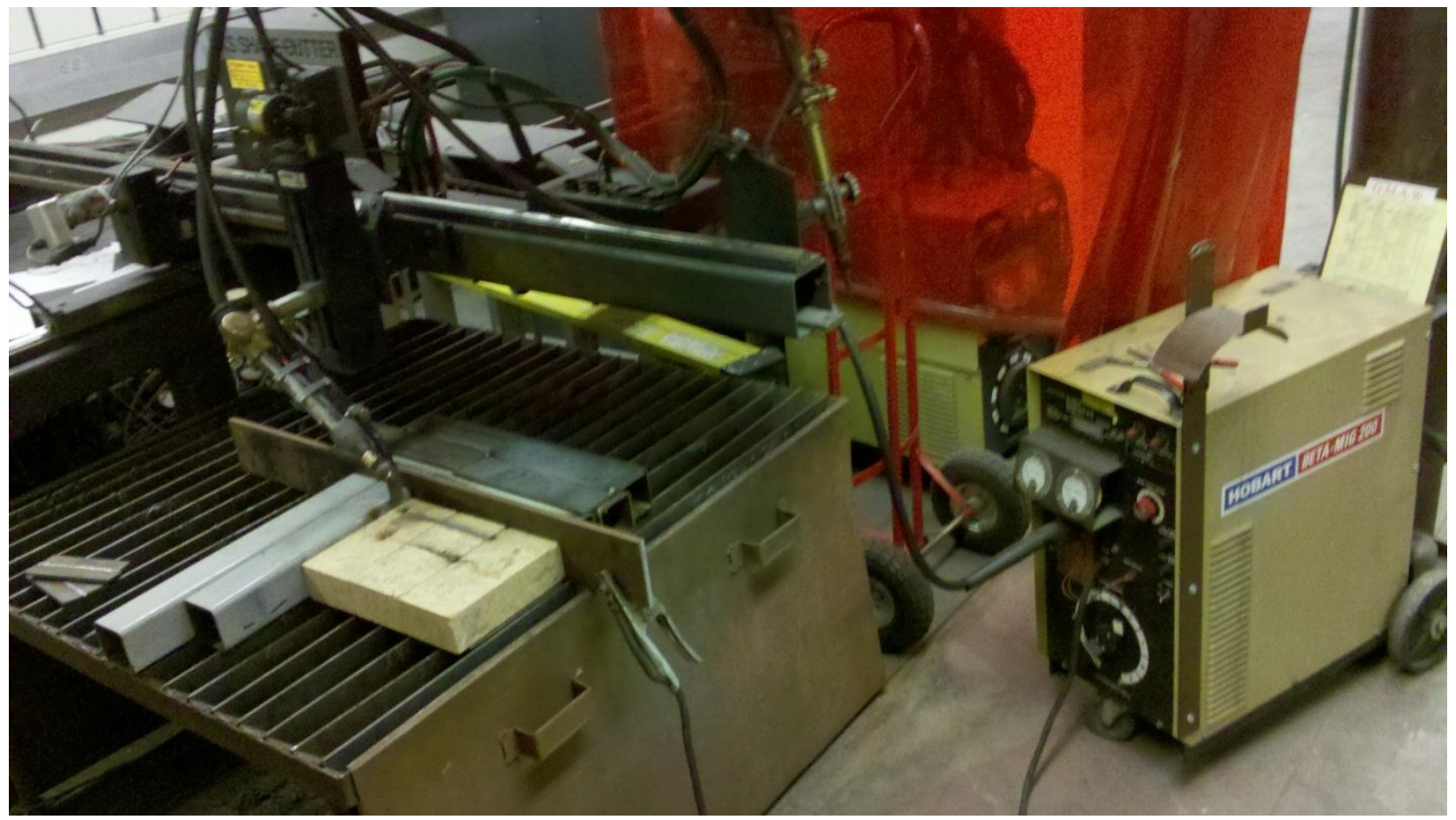

Figure 19. Welding equipment used during testing. 
Prior to welding the samples, the joints were aligned such that the material along the entire length of the joints touched and a tack weld was placed on either end of the joint where the material was to be discarded. This was done to reduce warpage that occurs during long welds that would create a gap near the end of the bead. See Figure 20 for the placement of the tack welds.

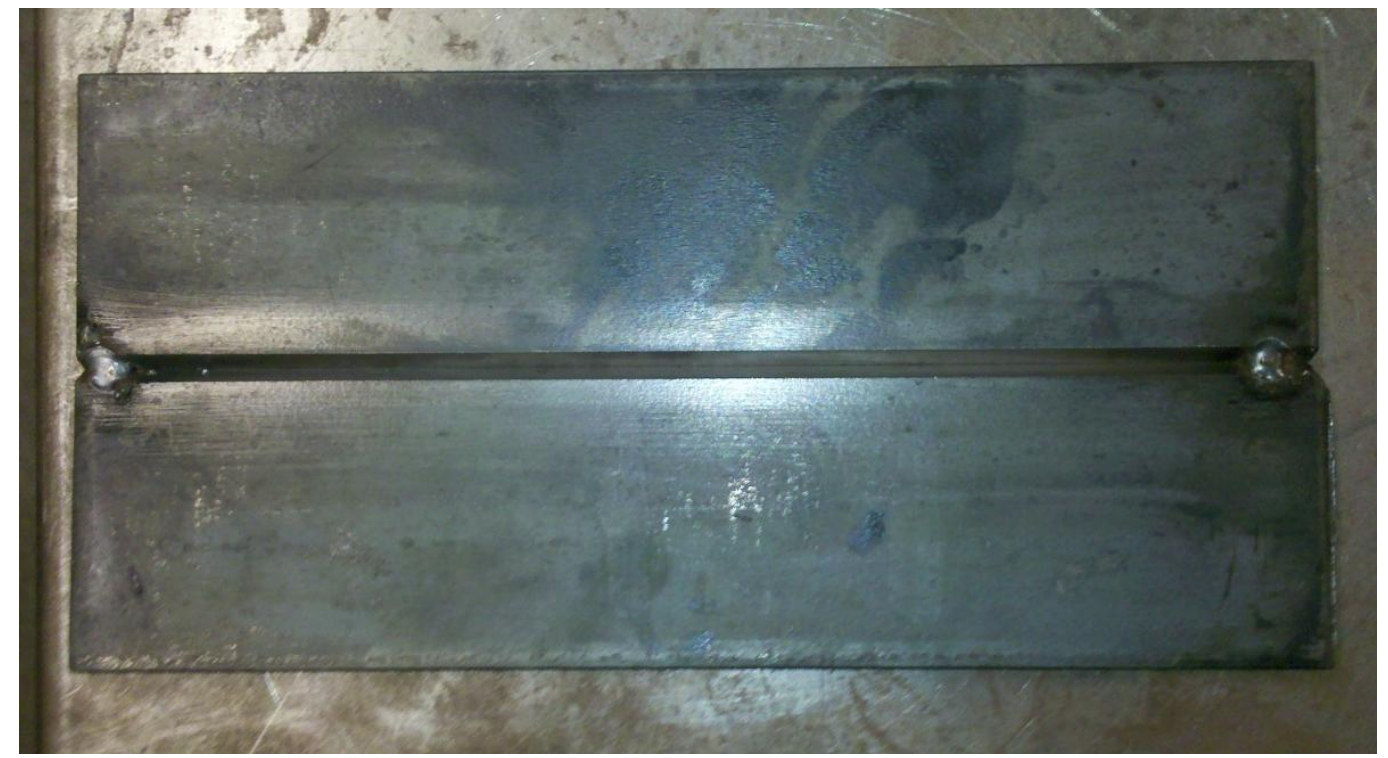

Figure 20. Tack welded sample.

Using the modified cutting table and MIG welder, the joints were welded using the manufacture's recommended settings for all of the welding parameters and the settings remained consistent while welding the samples. Table 2 shows the settings that were used during the welding process as recommended by the manufacturer. 
Table 2.

Weld Settings and Parameters.

\begin{tabular}{lc}
\hline Welding Wire & E-70S-8 \\
Wire Diameter & $0.035 \mathrm{~mm}$ \\
Gas & $\mathrm{C}_{25}\left(25 \% \mathrm{CO}_{2}\right.$ and $\left.75 \% \mathrm{Ar}\right)$ \\
Gas Rate & 30 Cubic Feet per Hour $(\mathrm{CFH})$ \\
Wire Feed Rate & 6 inches per second \\
Voltage & 20 Volts \\
Amperage & 200 Amps \\
Rate of Weld & 7 Inches per Minute (IPM) \\
\hline
\end{tabular}

All settings except the rate of weld and distance of the welding head to the sample were controlled by the settings and features of the welder. A simple horizontal line was programmed into the cutting table and the rate of weld was controlled by setting the travel speed of the head in inches per minute. The travel speed, which was not specified by the welder manufacturer, was set to create a full weld bead at the industry standard of a $60^{\circ}$ included angle. The distance of the welding head to the workpiece was tested prior to production of the samples in order to create a proper weld bead without causing damage to the tip of the welder. The distance from the sample to the welding head was set at 0.50 inches for all samples.

\section{Final machining procedures.}

Initially, the welded samples were to be sheared into approximately one inch sections using a stop jig in order to obtain the same width of each section, or coupon. However, it was found that the weld bead on the lesser included angles created twisting and cracking at the joint. Figure 21 displays the results of shearing a $0^{\circ}$ included angle. 


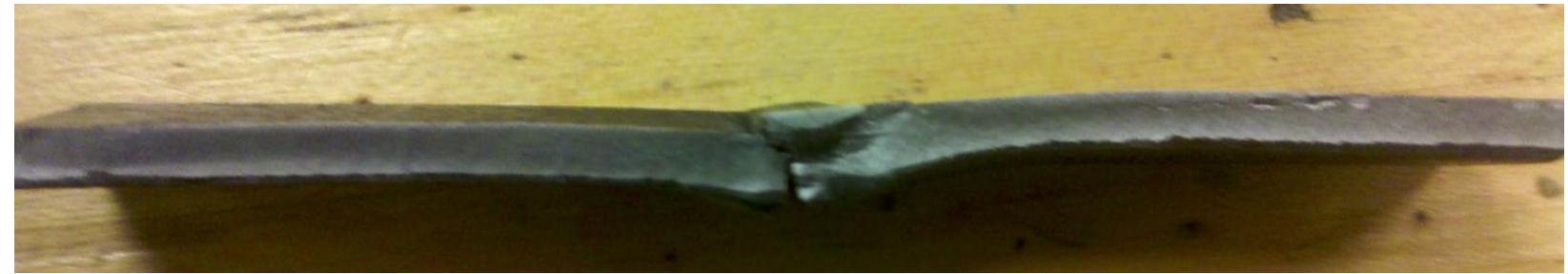

Figure 21. Cracking at weld joint due to shearing process.

After it was determined that shearing would affect the results of the research, it was determined that the coupons could be cut into one inch sections using the automated plasma cutting table. Figure 22 displays the coupons that were obtained from the plasma cutting process.
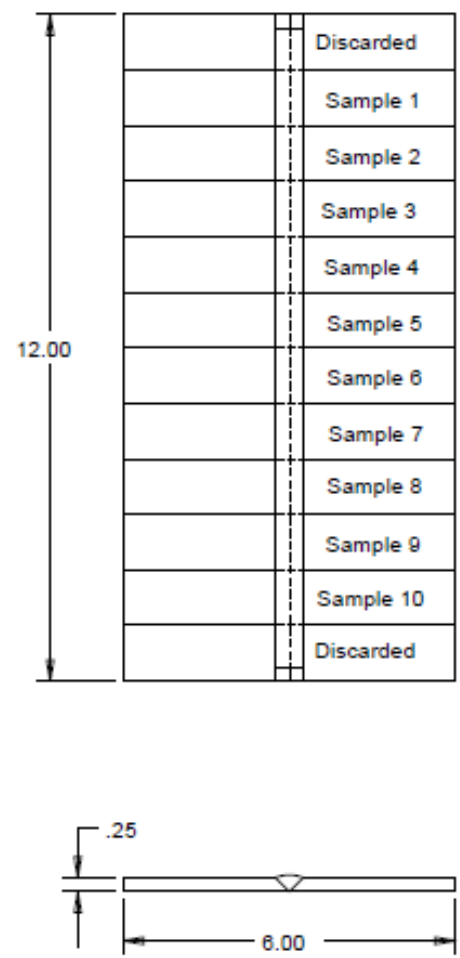

MATERIAL: ASTM A36 STEEL UNITS IN INCHES

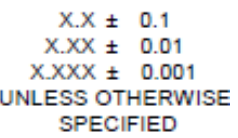

Figure 22. Plasma cut sections of welded plate. 
The heat treated edges that were created as a result of the plasma cut were then ground at the location of the necking process in order to reduce tool wear of the end mill during the necking process. A jig, as seen in Figure 23, was then designed and created in order to locate the coupons for machining in an Okuma MC 3-Vcomputer numerical control, or CNC, machine. Mechanical drawings of the jig can be found in Appendix A.

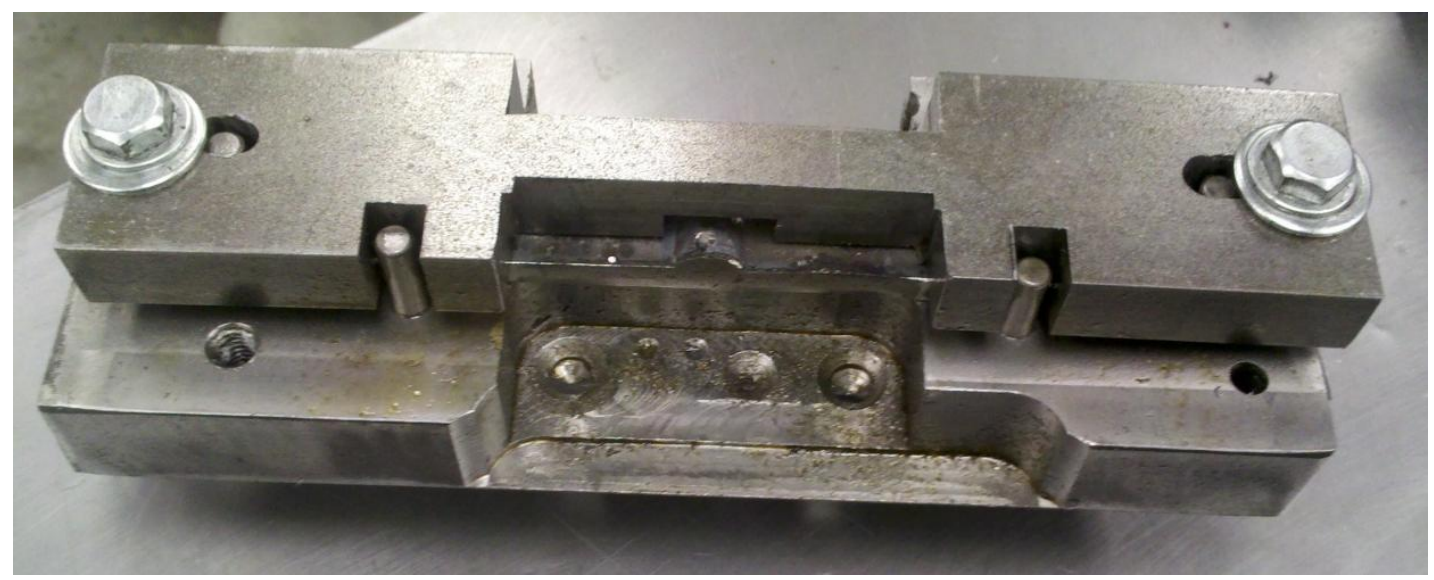

Figure 23. Jig used for the necking process.

The CNC machine (Figure 24) was programmed using the code found in Appendix B in order to create a uniform cross section of weld joint and surrounding parent material on all of the coupons. The jig was installed into the $\mathrm{CNC}$ machine and the machine was zeroed to the placement of the jig. To create the desired dimensions of the coupon a four flute, 0.75 inch diameter, single-ended, solid carbide end mill was utilized in the CNC machine. To increase cutting speeds and reduce tool wear, Rustlick ${ }^{\mathrm{TM}}$ WS-5050 multi-purpose, heavy-duty water soluble oil, diluted twenty parts water to one part oil, was used in the lubrication system of the CNC machine. Each coupon was then loaded into the jig and the program routine was run. Upon completion of the routine, the coupon was unloaded, the jig cleaned using compressed air, and 
another coupon was inserted into the jig. During the operation of the machine, the previously cut coupon was checked for dimensional accuracy using a micrometer.

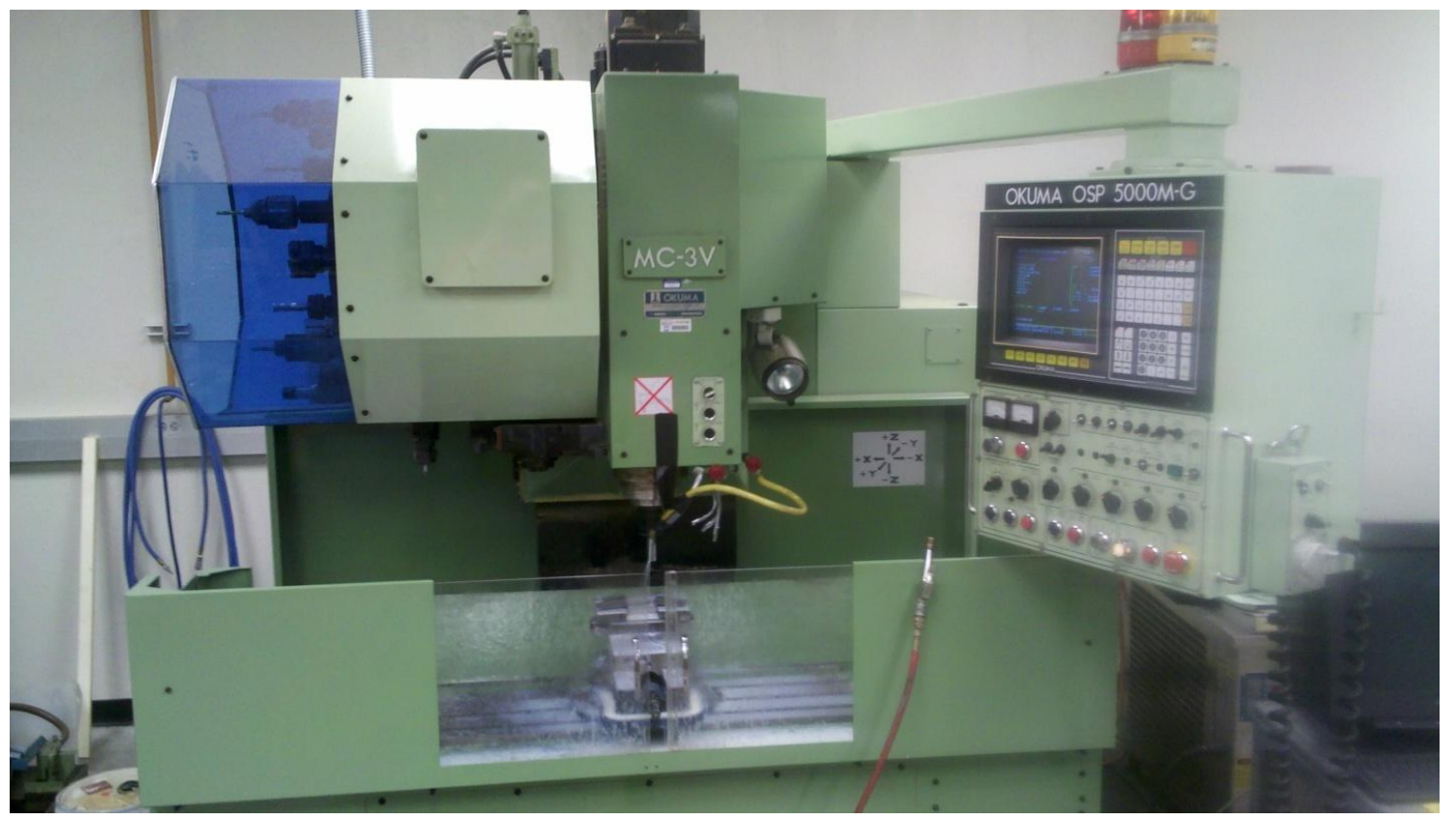

Figure 24. Okuma MC-3V Computer Numerical Control center.

Marks were then made 2 inches apart, approximately centered on the sample, using a permanent marker to be used as a reference for placing the sample in the tensile testing machine and to measure the elongation of each coupon after failure. A scribe was initially used to mark the coupons, but it was found that the marks were undistinguishable from the marks left by the tensile testing fixtures. Figure 25 shows the final dimensions of each coupon. 

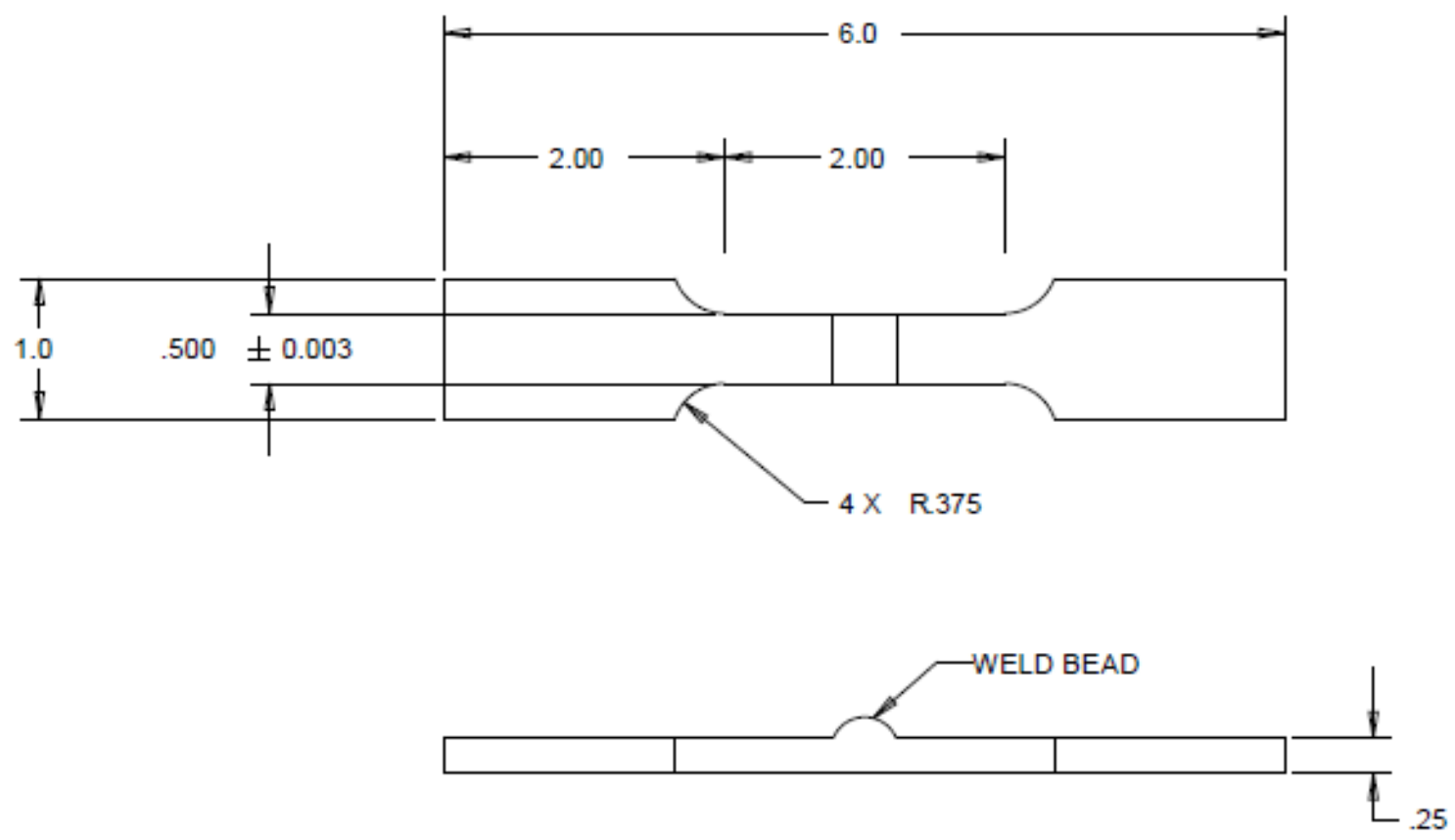

MATERIAL: ASTM A36 STEEL

UNITS IN INCHES

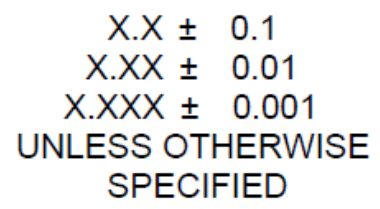

Figure 25. Final sample coupon dimensions.

\section{Tensile test testing procedures.}

The result of the previously mentioned processes yielded a population of ten coupons of each preparation angle and two sections that were discarded. The sections at the beginning and end of the weld were discarded because of the defects that are commonly found in the start and end of the weld bead (see Figure 26). 


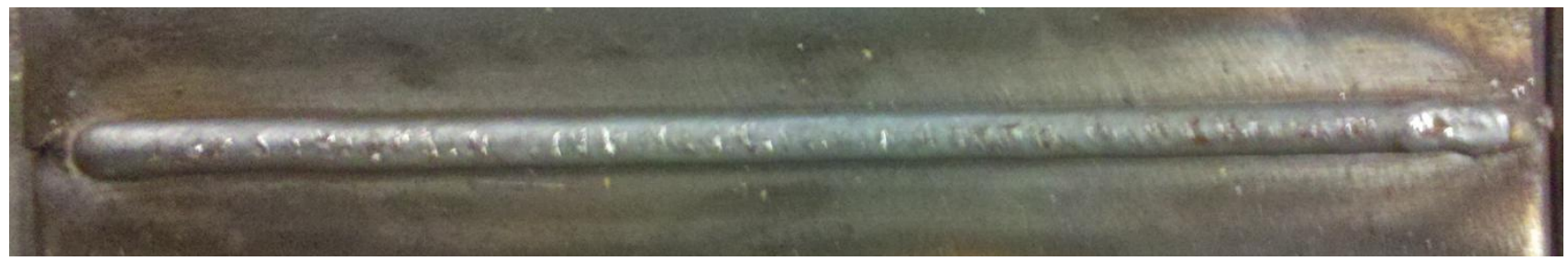

Figure 26. Defects at start and end of weld bead.

A United Testing Systems tensile tester, as seen in Figure 12, was used to perform the tensile testing of the coupons. The tensile tester contained a calibrated load cell connected to the upper gripping fixture that transfers load data to a digital readout on the machine in the form of pounds of force. The digital readout displays the current induced load and the maximum tensile load condition upon fracture of the coupon. The digital readout was reset to zero prior to each test. To induce tensile fracture of the coupon, the upper bridge was vertically translated by use of the internal controls of the tensile testing machine. The speed range was set to the low range and the travel potentiometer was set to a level of $25 \%$ of the maximum travel speed to induce a vertical displacement of the upper bridge at a rate of approximately 0.05 inches per minute. Upward travel commenced until complete fracture of the coupon occurred. The maximum load reading manually displayed on the digital readout was manually recorded in a spreadsheet for each of the 130 samples. Each sample was placed so that the marks previously made were at the edge of each gripping fixture in order to perform uniform testing. After fracture of each coupon, the process was repeated on all samples. All empirical data were then available for analysis with SPSS 18 statistical software for testing of the sample population. The percent elongation was calculated by subtracting the original distance of two inches from the measured distance after fracture and dividing by 100 . 


\section{Statistical procedures.}

Of interest was the variance present in the mechanical performance of the different preparation angles of the population. All empirical data captured (see Table 3) during the tensile testing session was entered into a spreadsheet and each preparation angle's population was coded into group ranges for analysis by SPSS 18 statistical software. Two individual variables were defined: Angle (included preparation angle) and Maximum Force (tensile strength). This recoding procedure allowed for between groups comparison of mean values with the One -Way Analysis of Variance (ANOVA) procedure. The total number of observations: N=130.

For the statistical analysis of this research, a Type I error rate of 0.05 was selected. A Type I error rate, designated as alpha $(\alpha)$, is also called the producer's risk and is related to the chance of falsely rejecting a null hypothesis 5 times in 100 chances, and produces a 95\% confidence interval. (Norusis, 2008) The alpha level of 0.05 was employed based on its frequency of use in manufacturing industry and research, as well as the regularity of occurrence in previous research related to this topic within the review of literature. The goal of this analysis was to reject, or fail to reject, the null hypotheses presented earlier in the research. The results of the statistical testing are fully reported in Chapter 4.

In response to the null hypothesis that there is no statistically significant correlation between the maximum force values of the sample population at various single-vee groove preparation angles and the stated industry standard, assessment was completed by using the OneWay ANOVA procedure. This method looks at how much the observations within each group vary as well as how much the group means vary to draw conclusions about the population means. If the sample means vary more than expected based on the variability of the observations within the groups, this concludes that the population means are not equal. 
To test the data, the One-Way ANOVA was defined with the pull value as the dependent variable and the group as the independent variable. Descriptive statistics yielded results for each group factor related to the mean values, standard deviation, standard error, $95 \%$ confidence interval upper and lower boundaries minimum, and maximum values. ANOVA results were supplied with the analysis of between groups and within group analysis that formulates the $F$ ratio and significance factor of the difference in population mean values assessed at the $95 \%$ confidence interval.

The ANOVA analysis requires the following assumptions: independent random samples have been taken from each population; the populations are normally distributed; [and] the population variances are all equal... The independence assumption means that there is no relationship between the observations in the different groups and between the observations in the same group. The normality assumption in analysis of variance... is not heavily dependent on the normality assumption. The equality-of-variance assumption can be checked by examining the spread of the observations in the boxplot. (Norusis, 2008)

Descriptive analysis from these additional tests were assessed, specifically the levels of skewness and kurtosis. The level of equality of variance was assessed by the Levene test.

\section{Summary}

This chapter restated the questions of the research and identified the elements of the research methodology required to answer these questions. Individual descriptions of the methods related to the research needs, constraint identification, material, equipment, production procedures, and tensile testing were defined. All testing parameters, error rates, and variable assignments associated to the statistical analysis methods utilized within SPSS were 
characterized. All of these elements were necessary to derive the results and supply the data reported in Chapter 4 in order to reject or fail to reject the null hypothesis. 


\section{Chapter 4}

\section{Results}

This research was designed to determine the variance in the tensile strength of welded single-vee butt joints as it correlates to the preparation angle of the joint. A population of coupons was produced using ASTM A36 carbon steel and the previously described methodology and subsequently tested for tensile strength to obtain empirical data of the tested relationships. The data were entered into SPSS 18 statistical software for examination.

A One-Way Analysis of Variance and Bonferroni multiple comparison procedure were utilized to analyze the test sample values, and confirmation of any prerequisite assumptions within these testing procedures were assessed by secondary and tertiary analysis, and by graphical means and nonparametric analysis. These analyses were used to accept or reject the null hypotheses at a 0.05 alpha level. The raw scores of each tensile pull test values (lb) at each preparation angle are documented in Table 3. 
Table 3

Tensile Strength Values at each Preparation Angle

\begin{tabular}{|c|c|c|c|}
\hline Angle $\left(^{\circ}\right)$ & Maximum Force (lb) & Percent Elongation (\%) & Point of Failure \\
\hline 0 & 4098.9 & 0.30 & Below \\
\hline 0 & 4303.3 & 0.40 & Below \\
\hline 0 & 5342.5 & 0.45 & Below \\
\hline 0 & 4715.6 & 0.35 & Below \\
\hline 0 & 2966.9 & 0.35 & Below \\
\hline 0 & 3205.4 & 0.60 & Below \\
\hline 0 & 3358.5 & 0.25 & Below \\
\hline 0 & 3377.3 & 0.65 & Below \\
\hline 0 & 4034.6 & 0.25 & Below \\
\hline 0 & 3751.9 & 0.35 & Below \\
\hline 10 & 5586.6 & 1.55 & Below \\
\hline 10 & 5806.3 & 0.85 & Below \\
\hline 10 & 5914.9 & 1.00 & Below \\
\hline 10 & 5966.2 & 1.40 & Below \\
\hline 10 & 6018.3 & 1.65 & Below \\
\hline 10 & 6083.5 & 2.25 & Below \\
\hline 10 & 5895.4 & 1.10 & Below \\
\hline 10 & 5817.8 & 1.30 & Below \\
\hline 10 & 5897.0 & 1.35 & Below \\
\hline 10 & 5940.2 & 2.45 & Above \\
\hline 20 & 5831.7 & 2.75 & Above \\
\hline 20 & 5615.1 & 1.95 & Above \\
\hline 20 & 5744.3 & 1.90 & Above \\
\hline 20 & 6086.9 & 2.40 & Above \\
\hline 20 & 6219.8 & 2.95 & Above \\
\hline 20 & 6172.2 & 3.25 & Above \\
\hline 20 & 5995.3 & 1.85 & Above \\
\hline 20 & 6095.1 & 2.35 & Above \\
\hline 20 & 6223.3 & 1.25 & Below \\
\hline 20 & 5398.6 & 1.90 & Below \\
\hline
\end{tabular}


Table 3 (Continued)

Tensile Strength Values at each Preparation Angle

\begin{tabular}{|c|c|c|c|}
\hline Angle $\left(^{\circ}\right)$ & Maximum Force (lb) & Percent Elongation (\%) & Point of Failure \\
\hline 30 & 4812.1 & 0.90 & Above \\
\hline 30 & 4663.9 & 0.95 & Above \\
\hline 30 & 6809.2 & 3.40 & Above \\
\hline 30 & 6582.2 & 2.70 & Above \\
\hline 30 & 6868.8 & 3.95 & Above \\
\hline 30 & 6732.8 & 2.25 & Above \\
\hline 30 & 6923.1 & 3.80 & Below \\
\hline 30 & 7116.3 & 4.90 & Below \\
\hline 30 & 6845.8 & 2.40 & Below \\
\hline 30 & 7280.9 & 3.80 & Below \\
\hline 40 & 6757.8 & 0.45 & Above \\
\hline 40 & 5973.9 & 2.90 & Above \\
\hline 40 & 6589.6 & 2.70 & Above \\
\hline 40 & 6678.7 & 1.60 & Above \\
\hline 40 & 6585.7 & 1.95 & Below \\
\hline 40 & 6140.4 & 1.40 & Above \\
\hline 40 & 6061.7 & 2.35 & Above \\
\hline 40 & 5943.9 & 1.25 & Above \\
\hline 40 & 6051.8 & 2.05 & Above \\
\hline 40 & 5312.4 & 1.95 & Above \\
\hline 50 & 7884.3 & 4.50 & Below \\
\hline 50 & 7552.7 & 5.30 & Below \\
\hline 50 & 6105.5 & 1.95 & Below \\
\hline 50 & 9014.3 & 22.05 & Parent Material \\
\hline 50 & 8243.7 & 3.40 & Above \\
\hline 50 & 9050.1 & 17.63 & Parent Material \\
\hline 50 & 8990.3 & 21.65 & Parent Material \\
\hline 50 & 9050.0 & 18.55 & Parent Material \\
\hline 50 & 8052.5 & 6.60 & Above \\
\hline 50 & 5907.0 & 1.05 & Above \\
\hline
\end{tabular}


Table 3 (Continued)

Tensile Strength Values at each Preparation Angle

\begin{tabular}{|c|c|c|c|}
\hline Angle $\left(^{\circ}\right)$ & Maximum Force (lb) & Percent Elongation (\%) & Point of Failure \\
\hline 60 & 4421.2 & 1.40 & Above \\
\hline 60 & 3104.8 & 0.95 & Above \\
\hline 60 & 3665.8 & 1.60 & Above \\
\hline 60 & 5687.9 & 0.95 & Above \\
\hline 60 & 7820.3 & 4.65 & Above \\
\hline 60 & 7450.5 & 3.95 & Above \\
\hline 60 & 7756.8 & 5.60 & Below \\
\hline 60 & 8962.2 & 17.9 & Parent Material \\
\hline 60 & 8848.4 & 20.75 & Parent Material \\
\hline 60 & 8048.5 & 4.85 & Below \\
\hline 70 & 5023.6 & 3.70 & Above \\
\hline 70 & 5352.1 & 3.30 & Above \\
\hline 70 & 7414.1 & 3.05 & Above \\
\hline 70 & 7051.5 & 3.00 & Above \\
\hline 70 & 6779.3 & 3.95 & Above \\
\hline 70 & 7800.3 & 3.35 & Above \\
\hline 70 & 8680.2 & 8.35 & Below \\
\hline 70 & 8705.5 & 8.15 & Below \\
\hline 70 & 8939.0 & 21.00 & Parent Material \\
\hline 70 & 5939.3 & 2.50 & Below \\
\hline 80 & 9136.9 & 13.55 & Parent Material \\
\hline 80 & 9283.4 & 18.95 & Parent Material \\
\hline 80 & 7940.9 & 6.30 & Above \\
\hline 80 & 9340.5 & 15.10 & Parent Material \\
\hline 80 & 9130.4 & 19.05 & Parent Material \\
\hline 80 & 9252.7 & 20.30 & Parent Material \\
\hline 80 & 9131.2 & 18.05 & Parent Material \\
\hline 80 & 9142.5 & 17.55 & Parent Material \\
\hline 80 & 7954.0 & 6.75 & Below \\
\hline 80 & 4684.7 & 1.05 & Below \\
\hline
\end{tabular}


Table 3 (Continued)

Tensile Strength Values at each Preparation Angle

\begin{tabular}{|c|c|c|c|}
\hline Angle $\left(^{\circ}\right)$ & Maximum Force (lb) & Percent Elongation $(\%)$ & Point of Failure \\
\hline 90 & 6668.4 & 3.90 & Above \\
\hline 90 & 5984.2 & 3.35 & Above \\
\hline 90 & 5812.5 & 3.60 & Above \\
\hline 90 & 5903.0 & 2.30 & Above \\
\hline 90 & 5898.1 & 2.65 & Above \\
\hline 90 & 5797.0 & 3.55 & Above \\
\hline 90 & 5793.4 & 3.60 & Above \\
\hline 90 & 5769.9 & 2.90 & Above \\
\hline 90 & 6087.7 & 2.75 & Above \\
\hline 90 & 7244.8 & 5.05 & Below \\
\hline 100 & 6114.2 & 3.45 & Below \\
\hline 100 & 6023.1 & 3.15 & Above \\
\hline 100 & 6756.9 & 3.60 & Above \\
\hline 100 & 5571.4 & 2.15 & Above \\
\hline 100 & 6037.3 & 2.00 & Above \\
\hline 100 & 5374.0 & 1.55 & Below \\
\hline 100 & 5341.2 & 1.90 & Below \\
\hline 100 & 5253.0 & 1.60 & Below \\
\hline 100 & 5476.8 & 2.40 & Below \\
\hline 100 & 5835.5 & 2.30 & Below \\
\hline 110 & 5783.2 & 3.60 & Above \\
\hline 110 & 5513.4 & 3.20 & Above \\
\hline 110 & 5624.6 & 4.10 & Below \\
\hline 110 & 5276.5 & 2.40 & Above \\
\hline 110 & 4819.8 & 3.50 & Above \\
\hline 110 & 5068.6 & 3.10 & Above \\
\hline 110 & 5544.1 & 2.25 & Above \\
\hline 110 & 5548.8 & 4.15 & Below \\
\hline 110 & 5580.0 & 5.05 & Below \\
\hline 110 & 5518.0 & 4.45 & Below \\
\hline
\end{tabular}


Table 3 (Continued)

Tensile Strength Values at each Preparation Angle

\begin{tabular}{cccc} 
Angle $\left({ }^{\circ}\right)$ & Maximum Force $(\mathrm{lb})$ & Percent Elongation $(\%)$ & Point of Failure \\
\hline 120 & 0 & 0 & Defect in Weld \\
120 & 6480.8 & 5.50 & Above \\
120 & 6649.7 & 4.75 & Above \\
120 & 5879.9 & 2.65 & Above \\
120 & 6081.5 & 3.75 & Above \\
120 & 6623.9 & 3.65 & Above \\
120 & 6924.5 & 5.20 & Below \\
120 & 6873.4 & 6.60 & Below \\
120 & 5456.4 & 4.45 & Below \\
120 & 4854.4 & 3.25 & Above \\
\hline
\end{tabular}

This chapter delineates the analysis and results of the stated null hypotheses, describes each of the tested statistical outputs and their principle values of interest, and offers statistical evidence related to the acceptance or rejection of the null hypotheses.

\section{Analysis and Results of the Null Hypotheses}

In regards to the analysis and results related to the null hypothesis, which states, "There is no statistically significant difference in the mean values of the tensile strength of the sample population at the various preparation angles," the following information is provided as a means of statistical assessment and validation. The most applicable form of statistical analysis for the data was One-Way ANOVA. This procedure is used for analysis-of-variance models with one or more factor variables and a single dependent variable. The condition of the normality and equality of variance is of interest within the population. Assessment of the first condition of normality was completed by creating a histogram with a normal curve superimposed over the data. This information is shown in Figure 27. 


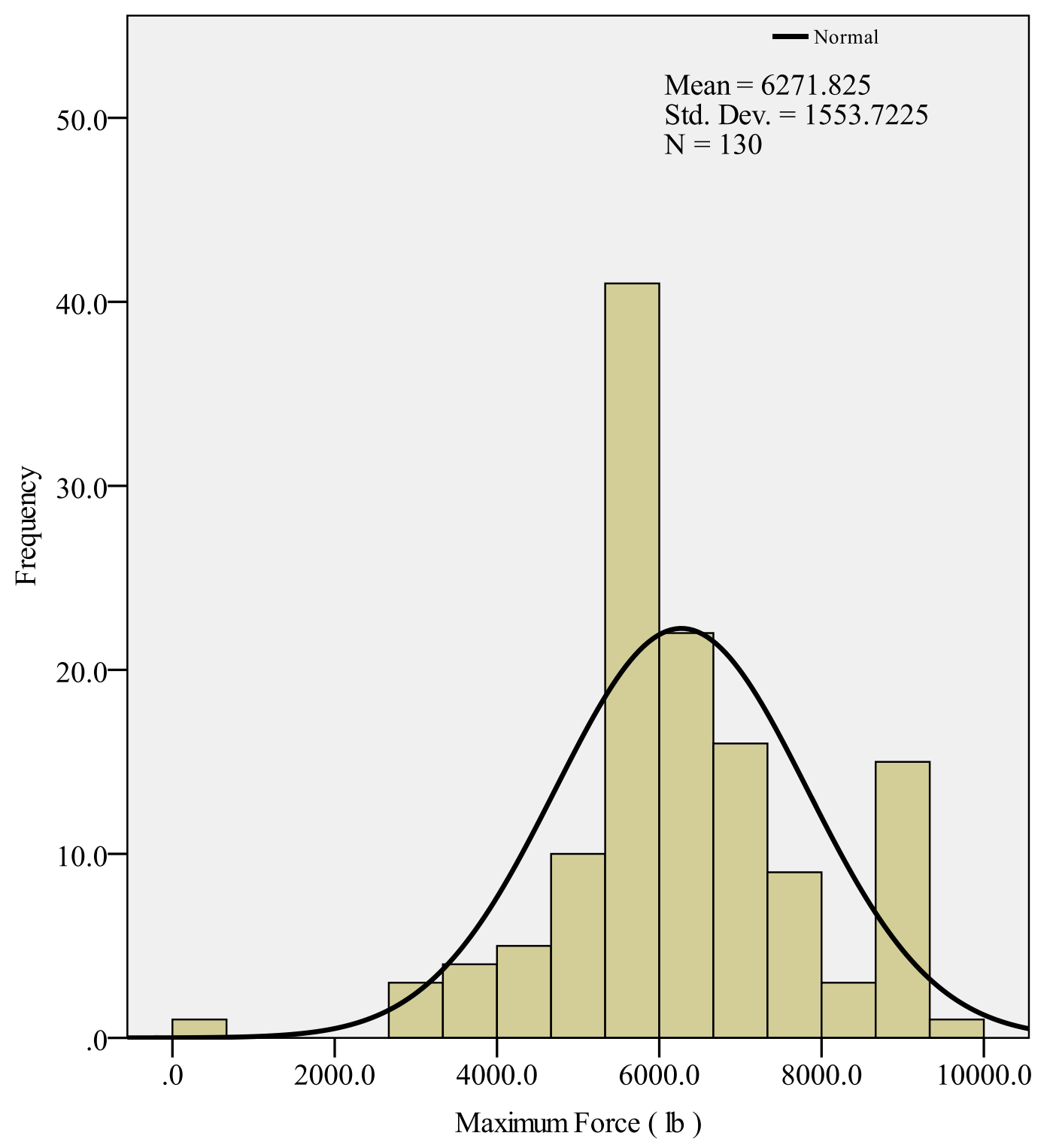

Figure 27. Histogram of population normality.

The histogram shows the frequency of occurrence for each range of data values. Visual inspection reveals that the data are somewhat negatively skewed resulting in a longer tail to the left with the additional indicator of the positive kurtosis as shown by the peak around the mean value of 6271.825 pounds. The number of occurrences in the $5333-6000$ range of tensile strength is disproportional to similar values of the right side of the mean associated with the 
normal distribution line. Assessment of these conditions affirmed the need for further normality testing by the use of the Q-Q Plot of normality shown in Figure 28.

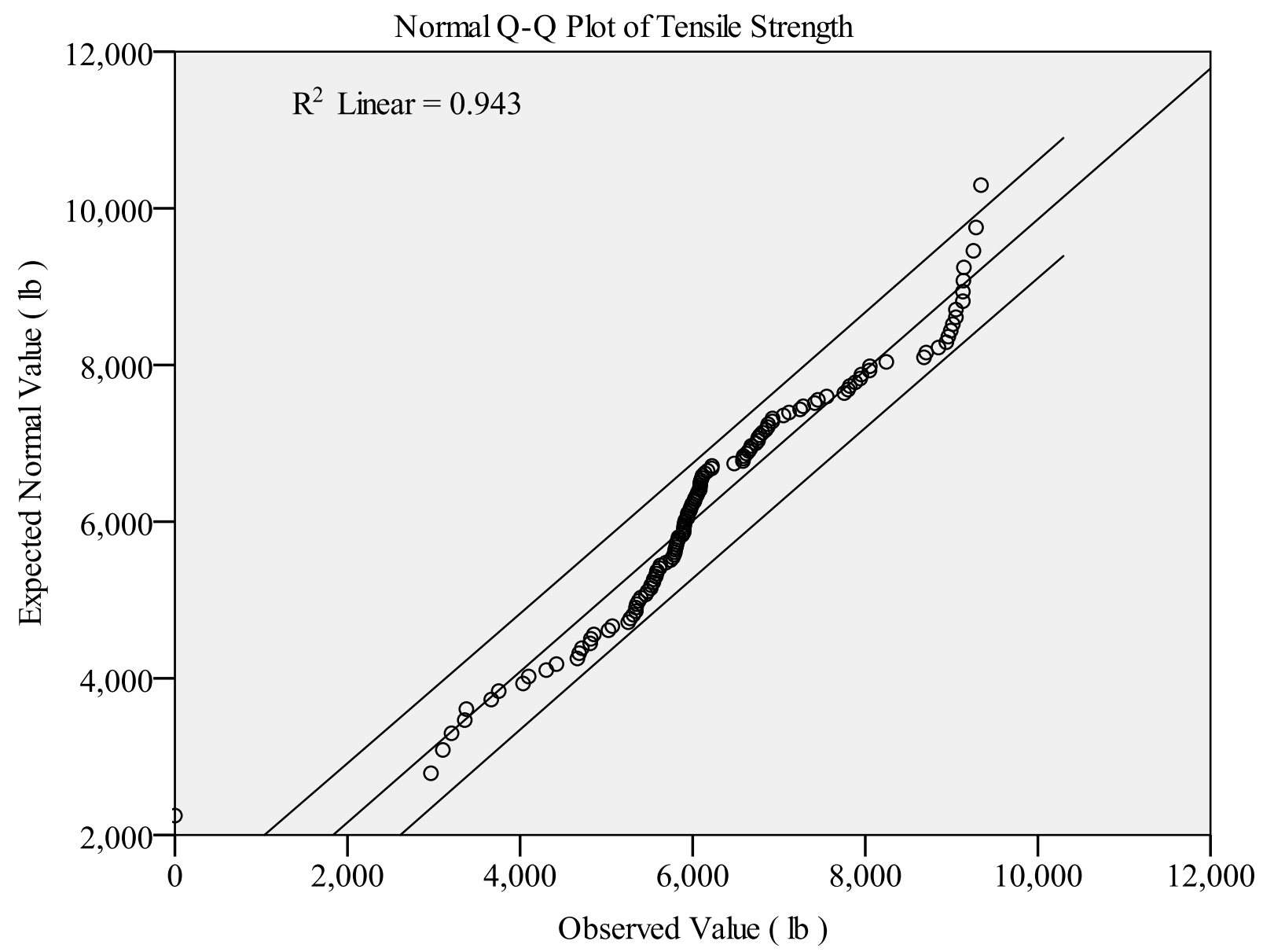

Figure 28. Q-Q plot of normality.

Visual examination of the data point locations in respect to the diagonal line, which represents the normal distribution, shows slight discrepancies on the upper ends of the data set. The majority of the data points conform within expectations, but the existence of outer tails of divergence constitutes further examination of normality by use of the Kolmogorov-Smirnov testing procedure. The results of the normality test associated with the Kolmogorov-Smirnov yielded a significance of $(p=.029)$, and this test offers some insight to the level of normality by 
the significance level being lower than the designated .05 Type I alpha rate. Normality would be rejected based on this statistic.

The other underlying assumption that must be addressed prior to assessment by use of ANOVA was the idea of the equality of variance of the sample population. Tests for the equality of population means assume that the data come from populations that have the same variance. If this assumption of homogeneity of variance is not met, the statistical test results may not be valid. This was quantified by the use of a Levene test as shown in Table 4 .

Table 4

Levene Test of Homogeneity of Variances

\begin{tabular}{cccc}
\multicolumn{4}{c}{ Maximum Force ( lb ) } \\
\hline $\begin{array}{l}\text { Levene } \\
\text { Statistic }\end{array}$ & df1 & df2 & Sig. \\
\hline 5.813 & 12 & 117 & .000 \\
\hline
\end{tabular}

The Levene test was utilized to test the assumption that each group of the independent population has the same variance. For this instance, equal variance is rejected based on the significance factor $(\mathrm{p}=.000)$ being smaller than our designated Type I alpha rate of .05 .

ANOVA is robust against violation of the assumptions. "The groups formed by the categories of the independent(s) should be equal or similar in sample size. The more the groups are similar in size, the more robust ANOVA will be with respect to violations of the assumptions of normality and homogeneity of variance." (Garson, Univariate GLM, ANOVA, and ANCOVA, 2009) Since all group sizes are equal, this leads the researcher to believe that the results of the testing will be valid.

Parametric testing of the difference of means of the group populations was completed by use of a One-Way ANOVA. For this analysis, Table 5 offers descriptive statistics for each 
preparation angle grouping. This ANOVA analysis was run with the variable Maximum Force being designated as the dependent variable, and the variable Preparation Angle being considered the independent variable.

Table 5

ANOVA Table of Descriptive Results

\begin{tabular}{ccccc}
\multicolumn{5}{c}{ Maximum Force $(\mathrm{lb})$} \\
\hline Angle $\left(^{\circ}\right)$ & $\mathrm{N}$ & Mean $(\mathrm{lb})$ & Std. Deviation & Std. Error \\
\hline 0 & 10 & 3915.490 & 738.2754 & 233.4632 \\
10 & 10 & 5892.620 & 136.2715 & 43.0928 \\
20 & 10 & 5938.230 & 280.8375 & 88.8086 \\
30 & 10 & 6463.510 & 930.2178 & 294.1607 \\
40 & 10 & 6209.590 & 445.8590 & 140.9930 \\
50 & 10 & 7985.040 & 1176.5231 & 372.0493 \\
60 & 10 & 6576.640 & 2177.7589 & 688.6678 \\
70 & 10 & 7168.490 & 1407.0367 & 444.9441 \\
80 & 10 & 8499.720 & 1440.2238 & 455.4387 \\
90 & 10 & 6095.900 & 483.5110 & 152.8996 \\
100 & 10 & 5778.340 & 467.2534 & 147.7585 \\
110 & 10 & 5427.700 & 289.3315 & 91.4947 \\
120 & 10 & 5582.450 & 2069.5019 & 654.4340 \\
Total & 130 & 6271.825 & 1553.7225 & 136.2705 \\
\hline
\end{tabular}

The results of the descriptive analysis shows that there was a total of 10 cases in each of the 13 sample groups, with the population wide mean total being 6271.825 pounds of force to induce failure of the coupon and the population standard deviation was 1553.7225 pounds. This is graphically shown in Figure 29, which shows the standard means plot produced with the OneWay ANOVA procedure. The variation in mean values shows an increase in tensile strength near the center of the data. This coincides with information provided in Chapter 2 that states that full penetration of the weld joint is required to produce the strongest joint. However, more filler 
metal is required if the preparation angle is too large, as shown by the decreasing pull values as the preparation angle increased.

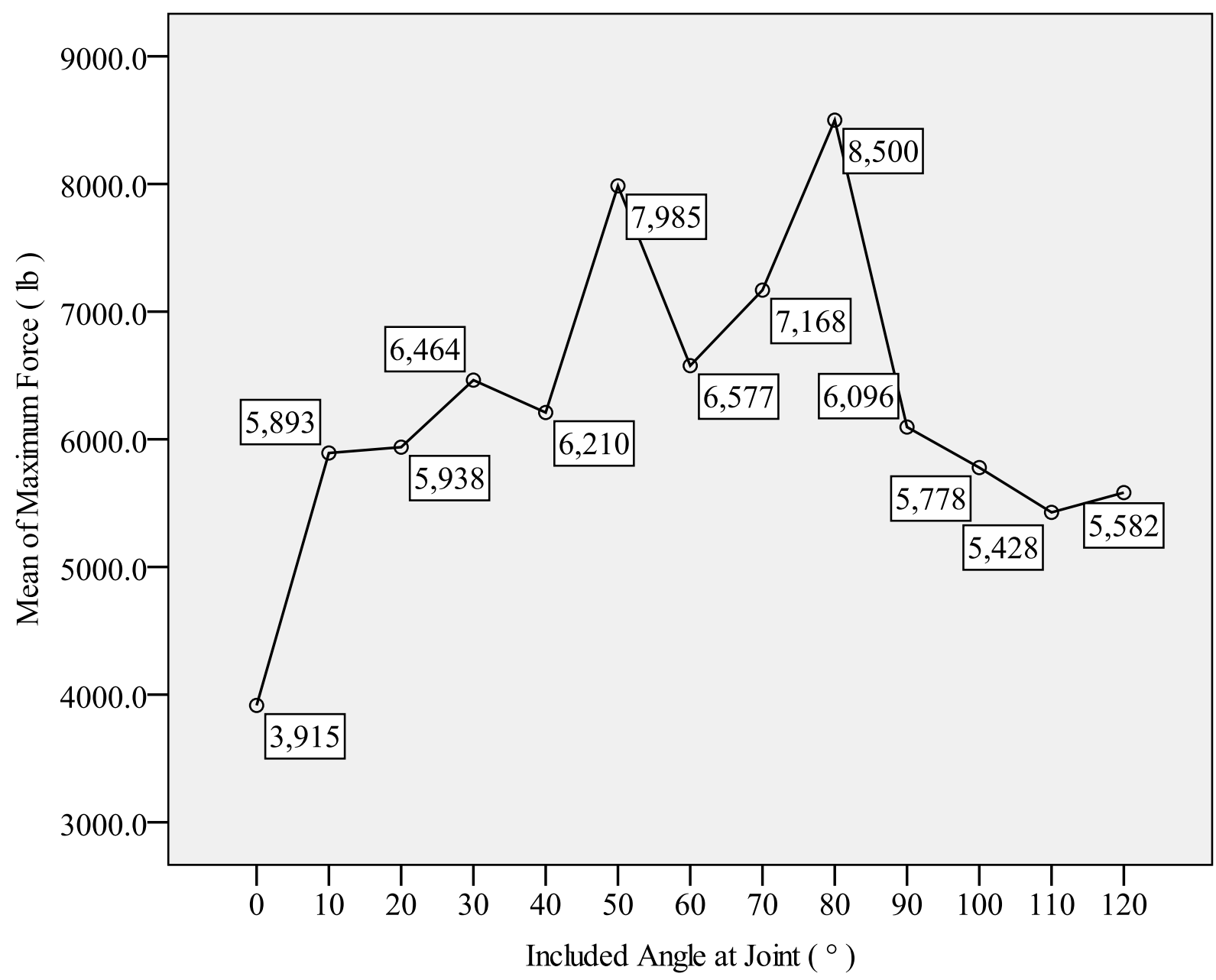

Figure 29. Standard plot of between group means within ANOVA

To statistically determine the significance of the level of variation between the groups of preparation angles, Table 6 shows the results of the parametric testing of the One-Way ANOVA. 
Table 6

ANOVA Test Statistics Results

Maximum Force ( $\mathrm{lb}$ )

\begin{tabular}{cccccc}
\hline & Sum of & & & & \\
& Squares & df & Mean Square & F & Sig. \\
\hline Between Groups & $161,100,000$ & 12 & $134,200,000.000$ & 10.444 & .000 \\
Within Groups & $150,400,000$ & 117 & 1285083.259 & & \\
Total & $311,400,000$ & 129 & & & \\
& & & & & \\
\hline
\end{tabular}

As depicted by the values in Table 6 that the ANOVA results were statistically significant at the .05 alpha level for the dependent variable of tensile strength based on the $F$ statistic (10.444) being higher than one. Since the relative significance level $(p=.000)$ the null hypothesis can be safely accepted. Since the results of the ANOVA testing were positive, a Bonferroni post-hoc analysis for between groups difference was completed and results can be found in Table 7. The Bonferroni post-hoc analysis was chosen because it holds the .05 alpha level for each comparison. 
Table 7

Bonferroni Post-Hoc Analysis Results

Maximum Force ( lb ): Bonferroni

\begin{tabular}{|c|c|c|c|c|c|c|}
\hline \multirow{2}{*}{$\begin{array}{l}\text { (I) } \\
\text { Included } \\
\text { Angle at } \\
\text { Joint }\end{array}$} & \multirow{2}{*}{$\begin{array}{l}(\mathrm{J}) \\
\text { Included } \\
\text { Angle at } \\
\text { Joint }\end{array}$} & \multirow{2}{*}{$\begin{array}{c}\text { Mean Difference } \\
(\mathrm{I}-\mathrm{J})\end{array}$} & \multirow{2}{*}{ Std. Error } & \multirow{2}{*}{ Sig. } & \multicolumn{2}{|c|}{$\begin{array}{l}\text { 95\% Confidence } \\
\text { Interval }\end{array}$} \\
\hline & & & & & $\begin{array}{l}\text { Lower } \\
\text { Bound }\end{array}$ & $\begin{array}{l}\text { Upper } \\
\text { Bound }\end{array}$ \\
\hline \multirow{12}{*}{0} & 10 & $-1977.13^{*}$ & 506.9681 & 0.013 & -3755.687 & -198.573 \\
\hline & 20 & $-2022.74^{*}$ & 506.9681 & 0.009 & -3801.297 & -244.183 \\
\hline & 30 & $-2548.02^{*}$ & 506.9681 & 0.000 & -4326.577 & -769.463 \\
\hline & 40 & $-2294.10^{*}$ & 506.9681 & 0.001 & -4072.657 & -515.543 \\
\hline & 50 & $-4069.55^{*}$ & 506.9681 & 0.000 & -5848.107 & -2290.993 \\
\hline & 60 & $-2661.15^{*}$ & 506.9681 & 0.000 & -4439.707 & -882.593 \\
\hline & 70 & $-3253.00^{*}$ & 506.9681 & 0.000 & -5031.557 & -1474.443 \\
\hline & 80 & $-4584.23^{*}$ & 506.9681 & 0.000 & -6362.787 & -2805.673 \\
\hline & 90 & $-2180.41^{*}$ & 506.9681 & 0.003 & -3958.967 & -401.853 \\
\hline & 100 & $-1862.85^{*}$ & 506.9681 & 0.028 & -3641.407 & -84.293 \\
\hline & 110 & -1512.21 & 506.9681 & 0.271 & -3290.767 & 266.347 \\
\hline & 120 & -1666.96 & 506.9681 & 0.104 & -3445.517 & 111.597 \\
\hline \multirow{12}{*}{10} & 0 & $1977.13^{*}$ & 506.9681 & 0.013 & 198.573 & 3755.687 \\
\hline & 20 & -45.61 & 506.9681 & 1.000 & -1824.167 & 1732.947 \\
\hline & 30 & -570.89 & 506.9681 & 1.000 & -2349.447 & 1207.667 \\
\hline & 40 & -316.97 & 506.9681 & 1.000 & -2095.527 & 1461.587 \\
\hline & 50 & $-2092.42^{*}$ & 506.9681 & 0.005 & -3870.977 & -313.863 \\
\hline & 60 & -684.02 & 506.9681 & 1.000 & -2462.577 & 1094.537 \\
\hline & 70 & -1275.87 & 506.9681 & 1.000 & -3054.427 & 502.687 \\
\hline & 80 & $-2607.10^{*}$ & 506.9681 & 0.000 & -4385.657 & -828.543 \\
\hline & 90 & -203.28 & 506.9681 & 1.000 & -1981.837 & 1575.277 \\
\hline & 100 & 114.28 & 506.9681 & 1.000 & -1664.277 & 1892.837 \\
\hline & 110 & 464.92 & 506.9681 & 1.000 & -1313.637 & 2243.477 \\
\hline & 120 & 310.17 & 506.9681 & 1.000 & -1468.387 & 2088.727 \\
\hline
\end{tabular}


Table 7 (Continued)

Bonferroni Post-Hoc Analysis Results

\begin{tabular}{|c|c|c|c|c|c|c|}
\hline \multirow{2}{*}{$\begin{array}{l}\text { (I) } \\
\text { Included } \\
\text { Angle at } \\
\text { Joint }\end{array}$} & \multirow{2}{*}{$\begin{array}{l}(\mathrm{J}) \\
\text { Included } \\
\text { Angle at } \\
\text { Joint }\end{array}$} & \multirow{2}{*}{$\begin{array}{c}\text { Mean Difference } \\
(\mathrm{I}-\mathrm{J})\end{array}$} & \multirow{2}{*}{ Std. Error } & \multirow{2}{*}{ Sig. } & \multicolumn{2}{|c|}{$\begin{array}{l}95 \% \text { Confidence } \\
\text { Interval }\end{array}$} \\
\hline & & & & & $\begin{array}{l}\text { Lower } \\
\text { Bound }\end{array}$ & $\begin{array}{l}\text { Upper } \\
\text { Bound }\end{array}$ \\
\hline \multirow{12}{*}{20} & 0 & $2022.74^{*}$ & 506.9681 & 0.009 & 244.183 & 3801.297 \\
\hline & 10 & 45.61 & 506.9681 & 1.000 & -1732.947 & 1824.167 \\
\hline & 30 & -525.28 & 506.9681 & 1.000 & -2303.837 & 1253.277 \\
\hline & 40 & -271.36 & 506.9681 & 1.000 & -2049.917 & 1507.197 \\
\hline & 50 & $-2046.81^{*}$ & 506.9681 & 0.008 & -3825.367 & -268.253 \\
\hline & 60 & -638.41 & 506.9681 & 1.000 & -2416.967 & 1140.147 \\
\hline & 70 & -1230.26 & 506.9681 & 1.000 & -3008.817 & 548.297 \\
\hline & 80 & $-2561.49^{*}$ & 506.9681 & 0.000 & -4340.047 & -782.933 \\
\hline & 90 & -157.67 & 506.9681 & 1.000 & -1936.227 & 1620.887 \\
\hline & 100 & 159.89 & 506.9681 & 1.000 & -1618.667 & 1938.447 \\
\hline & 110 & 510.53 & 506.9681 & 1.000 & -1268.027 & 2289.087 \\
\hline & 120 & 355.78 & 506.9681 & 1.000 & -1422.777 & 2134.337 \\
\hline \multirow{12}{*}{30} & 0 & $2548.02^{*}$ & 506.9681 & 0.000 & 769.463 & 4326.577 \\
\hline & 10 & 570.89 & 506.9681 & 1.000 & -1207.667 & 2349.447 \\
\hline & 20 & 525.28 & 506.9681 & 1.000 & -1253.277 & 2303.837 \\
\hline & 40 & 253.92 & 506.9681 & 1.000 & -1524.637 & 2032.477 \\
\hline & 50 & -1521.53 & 506.9681 & 0.256 & -3300.087 & 257.027 \\
\hline & 60 & -113.13 & 506.9681 & 1.000 & -1891.687 & 1665.427 \\
\hline & 70 & -704.98 & 506.9681 & 1.000 & -2483.537 & 1073.577 \\
\hline & 80 & $-2036.21^{*}$ & 506.9681 & 0.008 & -3814.767 & -257.653 \\
\hline & 90 & 367.61 & 506.9681 & 1.000 & -1410.947 & 2146.167 \\
\hline & 100 & 685.17 & 506.9681 & 1.000 & -1093.387 & 2463.727 \\
\hline & 110 & 1035.81 & 506.9681 & 1.000 & -742.747 & 2814.367 \\
\hline & 120 & 881.06 & 506.9681 & 1.000 & -897.497 & 2659.617 \\
\hline
\end{tabular}


Table 7 (Continued)

Bonferroni Post-Hoc Analysis Results

\begin{tabular}{|c|c|c|c|c|c|c|}
\hline \multirow{2}{*}{$\begin{array}{l}\text { (I) } \\
\text { Included } \\
\text { Angle at } \\
\text { Joint }\end{array}$} & \multirow{2}{*}{$\begin{array}{l}(\mathrm{J}) \\
\text { Included } \\
\text { Angle at } \\
\text { Joint }\end{array}$} & \multirow{2}{*}{$\begin{array}{c}\text { Mean Difference } \\
(\mathrm{I}-\mathrm{J})\end{array}$} & \multirow{2}{*}{ Std. Error } & \multirow{2}{*}{ Sig. } & \multicolumn{2}{|c|}{$\begin{array}{l}\text { 95\% Confidence } \\
\text { Interval }\end{array}$} \\
\hline & & & & & $\begin{array}{l}\text { Lower } \\
\text { Bound }\end{array}$ & $\begin{array}{l}\text { Upper } \\
\text { Bound }\end{array}$ \\
\hline \multirow{12}{*}{40} & 0 & $2294.10^{*}$ & 506.9681 & 0.001 & 515.543 & 4072.657 \\
\hline & 10 & 316.97 & 506.9681 & 1.000 & -1461.587 & 2095.527 \\
\hline & 20 & 271.36 & 506.9681 & 1.000 & -1507.197 & 2049.917 \\
\hline & 30 & -253.92 & 506.9681 & 1.000 & -2032.477 & 1524.637 \\
\hline & 50 & -1775.45 & 506.9681 & 0.051 & -3554.007 & 3.107 \\
\hline & 60 & -367.05 & 506.9681 & 1.000 & -2145.607 & 1411.507 \\
\hline & 70 & -958.90 & 506.9681 & 1.000 & -2737.457 & 819.657 \\
\hline & 80 & $-2290.13^{*}$ & 506.9681 & 0.001 & -4068.687 & -511.573 \\
\hline & 90 & 113.69 & 506.9681 & 1.000 & -1664.867 & 1892.247 \\
\hline & 100 & 431.25 & 506.9681 & 1.000 & -1347.307 & 2209.807 \\
\hline & 110 & 781.89 & 506.9681 & 1.000 & -996.667 & 2560.447 \\
\hline & 120 & 627.14 & 506.9681 & 1.000 & -1151.417 & 2405.697 \\
\hline \multirow{12}{*}{50} & 0 & $4069.55^{*}$ & 506.9681 & 0.000 & 2290.993 & 5848.107 \\
\hline & 10 & $2092.42^{*}$ & 506.9681 & 0.005 & 313.863 & 3870.977 \\
\hline & 20 & $2046.81^{*}$ & 506.9681 & 0.008 & 268.253 & 3825.367 \\
\hline & 30 & 1521.53 & 506.9681 & 0.256 & -257.027 & 3300.087 \\
\hline & 40 & 1775.45 & 506.9681 & 0.051 & -3.107 & 3554.007 \\
\hline & 60 & 1408.40 & 506.9681 & 0.497 & -370.157 & 3186.957 \\
\hline & 70 & 816.55 & 506.9681 & 1.000 & -962.007 & 2595.107 \\
\hline & 80 & -514.68 & 506.9681 & 1.000 & -2293.237 & 1263.877 \\
\hline & 90 & $1889.14^{*}$ & 506.9681 & 0.023 & 110.583 & 3667.697 \\
\hline & 100 & $2206.70^{*}$ & 506.9681 & 0.002 & 428.143 & 3985.257 \\
\hline & 110 & $2557.34^{*}$ & 506.9681 & 0.000 & 778.783 & 4335.897 \\
\hline & 120 & $2402.59^{*}$ & 506.9681 & 0.000 & 624.033 & 4181.147 \\
\hline
\end{tabular}


Table 7 (Continued)

Bonferroni Post-Hoc Analysis Results

\begin{tabular}{|c|c|c|c|c|c|c|}
\hline \multirow{2}{*}{$\begin{array}{l}\text { (I) } \\
\text { Included } \\
\text { Angle at } \\
\text { Joint }\end{array}$} & \multirow{2}{*}{$\begin{array}{l}(\mathrm{J}) \\
\text { Included } \\
\text { Angle at } \\
\text { Joint }\end{array}$} & \multirow{2}{*}{$\begin{array}{c}\text { Mean Difference } \\
(\mathrm{I}-\mathrm{J})\end{array}$} & \multirow{2}{*}{ Std. Error } & \multirow{2}{*}{ Sig. } & \multicolumn{2}{|c|}{$\begin{array}{l}\text { 95\% Confidence } \\
\text { Interval }\end{array}$} \\
\hline & & & & & $\begin{array}{l}\text { Lower } \\
\text { Bound }\end{array}$ & $\begin{array}{l}\text { Upper } \\
\text { Bound }\end{array}$ \\
\hline \multirow{12}{*}{60} & 0 & $2661.15^{*}$ & 506.9681 & 0.000 & 882.593 & 4439.707 \\
\hline & 10 & 684.02 & 506.9681 & 1.000 & -1094.537 & 2462.577 \\
\hline & 20 & 638.41 & 506.9681 & 1.000 & -1140.147 & 2416.967 \\
\hline & 30 & 113.13 & 506.9681 & 1.000 & -1665.427 & 1891.687 \\
\hline & 40 & 367.05 & 506.9681 & 1.000 & -1411.507 & 2145.607 \\
\hline & 50 & -1408.40 & 506.9681 & 0.497 & -3186.957 & 370.157 \\
\hline & 70 & -591.85 & 506.9681 & 1.000 & -2370.407 & 1186.707 \\
\hline & 80 & $-1923.08^{*}$ & 506.9681 & 0.018 & -3701.637 & -144.523 \\
\hline & 90 & 480.74 & 506.9681 & 1.000 & -1297.817 & 2259.297 \\
\hline & 100 & 798.30 & 506.9681 & 1.000 & -980.257 & 2576.857 \\
\hline & 110 & 1148.94 & 506.9681 & 1.000 & -629.617 & 2927.497 \\
\hline & 120 & 994.19 & 506.9681 & 1.000 & -784.367 & 2772.747 \\
\hline \multirow{12}{*}{70} & 0 & $3253.00^{*}$ & 506.9681 & 0.000 & 1474.443 & 5031.557 \\
\hline & 10 & 1275.87 & 506.9681 & 1.000 & -502.687 & 3054.427 \\
\hline & 20 & 1230.26 & 506.9681 & 1.000 & -548.297 & 3008.817 \\
\hline & 30 & 704.98 & 506.9681 & 1.000 & -1073.577 & 2483.537 \\
\hline & 40 & 958.90 & 506.9681 & 1.000 & -819.657 & 2737.457 \\
\hline & 50 & -816.55 & 506.9681 & 1.000 & -2595.107 & 962.007 \\
\hline & 60 & 591.85 & 506.9681 & 1.000 & -1186.707 & 2370.407 \\
\hline & 80 & -1331.23 & 506.9681 & 0.764 & -3109.787 & 447.327 \\
\hline & 90 & 1072.59 & 506.9681 & 1.000 & -705.967 & 2851.147 \\
\hline & 100 & 1390.15 & 506.9681 & 0.551 & -388.407 & 3168.707 \\
\hline & 110 & 1740.79 & 506.9681 & 0.064 & -37.767 & 3519.347 \\
\hline & 120 & 1586.04 & 506.9681 & 0.173 & -192.517 & 3364.597 \\
\hline
\end{tabular}


Table 7 (Continued)

Bonferroni Post-Hoc Analysis Results

\begin{tabular}{|c|c|c|c|c|c|c|}
\hline \multirow{2}{*}{$\begin{array}{l}\text { (I) } \\
\text { Included } \\
\text { Angle at } \\
\text { Joint }\end{array}$} & \multirow{2}{*}{$\begin{array}{l}(\mathrm{J}) \\
\text { Included } \\
\text { Angle at } \\
\text { Joint }\end{array}$} & \multirow{2}{*}{$\begin{array}{c}\text { Mean Difference } \\
(\mathrm{I}-\mathrm{J})\end{array}$} & \multirow{2}{*}{ Std. Error } & \multirow{2}{*}{ Sig. } & \multicolumn{2}{|c|}{$\begin{array}{l}95 \% \text { Confidence } \\
\text { Interval }\end{array}$} \\
\hline & & & & & $\begin{array}{l}\text { Lower } \\
\text { Bound }\end{array}$ & $\begin{array}{l}\text { Upper } \\
\text { Bound }\end{array}$ \\
\hline \multirow{12}{*}{80} & 0 & $4584.23^{*}$ & 506.9681 & 0.000 & 2805.673 & 6362.787 \\
\hline & 10 & $2607.10^{*}$ & 506.9681 & 0.000 & 828.543 & 4385.657 \\
\hline & 20 & $2561.49^{*}$ & 506.9681 & 0.000 & 782.933 & 4340.047 \\
\hline & 30 & $2036.21^{*}$ & 506.9681 & 0.008 & 257.653 & 3814.767 \\
\hline & 40 & $2290.13^{*}$ & 506.9681 & 0.001 & 511.573 & 4068.687 \\
\hline & 50 & 514.68 & 506.9681 & 1.000 & -1263.877 & 2293.237 \\
\hline & 60 & $1923.08^{*}$ & 506.9681 & 0.018 & 144.523 & 3701.637 \\
\hline & 70 & 1331.23 & 506.9681 & 0.764 & -447.327 & 3109.787 \\
\hline & 90 & $2403.82^{*}$ & 506.9681 & 0.000 & 625.263 & 4182.377 \\
\hline & 100 & $2721.38^{*}$ & 506.9681 & 0.000 & 942.823 & 4499.937 \\
\hline & 110 & $3072.02^{*}$ & 506.9681 & 0.000 & 1293.463 & 4850.577 \\
\hline & 120 & $2917.27^{*}$ & 506.9681 & 0.000 & 1138.713 & 4695.827 \\
\hline \multirow{12}{*}{90} & 0 & $2180.41^{*}$ & 506.9681 & 0.003 & 401.853 & 3958.967 \\
\hline & 10 & 203.28 & 506.9681 & 1.000 & -1575.277 & 1981.837 \\
\hline & 20 & 157.67 & 506.9681 & 1.000 & -1620.887 & 1936.227 \\
\hline & 30 & -367.61 & 506.9681 & 1.000 & -2146.167 & 1410.947 \\
\hline & 40 & -113.69 & 506.9681 & 1.000 & -1892.247 & 1664.867 \\
\hline & 50 & $-1889.14^{*}$ & 506.9681 & 0.023 & -3667.697 & -110.583 \\
\hline & 60 & -480.74 & 506.9681 & 1.000 & -2259.297 & 1297.817 \\
\hline & 70 & -1072.59 & 506.9681 & 1.000 & -2851.147 & 705.967 \\
\hline & 80 & $-2403.82^{*}$ & 506.9681 & 0.000 & -4182.377 & -625.263 \\
\hline & 100 & 317.56 & 506.9681 & 1.000 & -1460.997 & 2096.117 \\
\hline & 110 & 668.2 & 506.9681 & 1.000 & -1110.357 & 2446.757 \\
\hline & 120 & 513.45 & 506.9681 & 1.000 & -1265.107 & 2292.007 \\
\hline
\end{tabular}


Table 7 (Continued)

Bonferroni Post-Hoc Analysis Results

(I) (J)

Included Included Mean Difference Angle at Angle at Joint Joint

(I-J)

\begin{tabular}{|c|c|c|c|c|c|c|}
\hline \multirow{12}{*}{100} & 0 & $1862.85^{*}$ & 506.9681 & 0.028 & 84.293 & 3641.407 \\
\hline & 10 & -114.28 & 506.9681 & 1.000 & -1892.837 & 1664.277 \\
\hline & 20 & -159.89 & 506.9681 & 1.000 & -1938.447 & 1618.667 \\
\hline & 30 & -685.17 & 506.9681 & 1.000 & -2463.727 & 1093.387 \\
\hline & 40 & -431.25 & 506.9681 & 1.000 & -2209.807 & 1347.307 \\
\hline & 50 & $-2206.70^{*}$ & 506.9681 & 0.002 & -3985.257 & -428.143 \\
\hline & 60 & -798.3 & 506.9681 & 1.000 & -2576.857 & 980.257 \\
\hline & 70 & -1390.15 & 506.9681 & 0.551 & -3168.707 & 388.407 \\
\hline & 80 & $-2721.38^{*}$ & 506.9681 & 0.000 & -4499.937 & -942.823 \\
\hline & 90 & -317.56 & 506.9681 & 1.000 & -2096.117 & 1460.997 \\
\hline & 110 & 350.64 & 506.9681 & 1.000 & -1427.917 & 2129.197 \\
\hline & 120 & 195.89 & 506.9681 & 1.000 & -1582.667 & 1974.447 \\
\hline \multirow{12}{*}{110} & 0 & 1512.21 & 506.9681 & 0.271 & -266.347 & 3290.767 \\
\hline & 10 & -464.92 & 506.9681 & 1.000 & -2243.477 & 1313.637 \\
\hline & 20 & -510.53 & 506.9681 & 1.000 & -2289.087 & 1268.027 \\
\hline & 30 & -1035.81 & 506.9681 & 1.000 & -2814.367 & 742.747 \\
\hline & 40 & -781.89 & 506.9681 & 1.000 & -2560.447 & 996.667 \\
\hline & 50 & $-2557.34^{*}$ & 506.9681 & 0.000 & -4335.897 & -778.783 \\
\hline & 60 & -1148.94 & 506.9681 & 1.000 & -2927.497 & 629.617 \\
\hline & 70 & -1740.79 & 506.9681 & 0.064 & -3519.347 & 37.767 \\
\hline & 80 & $-3072.02^{*}$ & 506.9681 & 0.000 & -4850.577 & -1293.463 \\
\hline & 90 & -668.2 & 506.9681 & 1.000 & -2446.757 & 1110.357 \\
\hline & 100 & -350.64 & 506.9681 & 1.000 & -2129.197 & 1427.917 \\
\hline & 120 & -154.75 & 506.9681 & 1.000 & -1933.307 & 1623.807 \\
\hline
\end{tabular}
Bound Bound

95\% Confidence Interval

Std. Error Sig. Lower Upper 
Table 7 (Continued)

Bonferroni Post-Hoc Analysis Results

(I) (J)

Included Included Mean Difference

Angle at Angle at

Joint Joint

\begin{tabular}{ccccccc}
\hline & 0 & 1666.96 & 506.9681 & 0.104 & -111.597 & 3445.517 \\
& 10 & -310.17 & 506.9681 & 1.000 & -2088.727 & 1468.387 \\
20 & -355.78 & 506.9681 & 1.000 & -2134.337 & 1422.777 \\
& 30 & -881.06 & 506.9681 & 1.000 & -2659.617 & 897.497 \\
& 40 & -627.14 & 506.9681 & 1.000 & -2405.697 & 1151.417 \\
& 50 & $-2402.59^{*}$ & 506.9681 & 0.000 & -4181.147 & -624.033 \\
& 60 & -994.19 & 506.9681 & 1.000 & -2772.747 & 784.367 \\
& 70 & -1586.04 & 506.9681 & 0.173 & -3364.597 & 192.517 \\
& 80 & $-2917.27^{*}$ & 506.9681 & 0.000 & -4695.827 & -1138.713 \\
& 90 & -513.45 & 506.9681 & 1.000 & -2292.007 & 1265.107 \\
& 100 & -195.89 & 506.9681 & 1.000 & -1974.447 & 1582.667 \\
& 110 & 154.75 & 506.9681 & 1.000 & -1623.807 & 1933.307 \\
\hline
\end{tabular}

*. The mean difference is significant at the 0.05 level.

95\% Confidence

Std. Error Sig. Lower Upper

Bound Bound

3445.517

66

Using the information found in Table 7, we can accept Null Hypothesis 2, which states that, "The industry standard of $60^{\circ}$ included preparation angle of single-vee butt joints will not yield the highest tensile strength." We can see from Figure 29 that the $50^{\circ}, 70^{\circ}$, and $80^{\circ}$ preparation angles yield a higher mean tensile strength than that of the industry standard of $60^{\circ}$. However, from Table 8 we see that the $80^{\circ}$ preparation angle is the only angle that has a statistically significant difference at $(\mathrm{p}=.018)$. 


\section{Chapter 5}

\section{Summary, findings, \& conclusions}

The production of single-vee butt welds involves a vast set of interdependent elements that assimilate to create the final joint, and a further understanding of this process is needed to isolate potential areas that could result in quality issues. The purpose of this study was to isolate a single variable in this process, the preparation angle at the joint, and delineate its effect on the tensile strength of the joint. This phenomenon is readily prevalent in structural applications where a load is applied to a joint.

The literature review described the complex nature of the formation of weld joints, and defined the effect of the various elements of the welding procedure. These elements ranged from welding method, joint type, gas type, arc type, and material conditions. It was shown that the final geometric composition of the weld joint played an important role on the amount of force required to induce complete mechanical fracture of the joint. This geometric composition and resistance to tensile failure is a direct result of the preparation angle of the butt joint.

With all of the basic elemental components of this process, can one identify the effect of a single variable on the final product, and if so, to what magnitude does its effect have? This was the underlying question of this study. This research was designed to determine the level of variance in the tensile strength of single-vee butt joints as it relates to the preparation angles of the joints. 
In order to assess the level of interaction of the tested variables, test samples were produced with single-vee butt joints at various preparation angles. These samples were tested for tensile pull resistance to determine the amount of force required to induce complete fracture of the weld joint. These data were statistically assessed by SPSS 18 statistical software for evaluation of potential findings.

\section{Findings and Conclusions}

Based on the analysis of the data from the tensile testing of the sample population of preparation angles, the following findings and conclusions are presented in respect to their associated null hypothesis.

Null Hypothesis 1: It was demonstrated by the results of the analytical findings that the variance of mean values of tensile fracture between various preparation angles was statistically significant. The results of the One-Way ANOVA showed a difference in the mean values of tensile strength based on the angle of the joint.

Null Hypothesis 2: From Figure 27, it was shown that the industry standard of $60^{\circ}$ did not yield the highest mean tensile strength of the samples. From the Bonferroni post-hoc

analysis of the data, it was found that an $80^{\circ}$ included preparation angle yields a statistically significant maximum force that is higher than that of the industry standard.

While this information is conclusive for the characteristics of this particular research that was conducted within certain limitations, it should not be assumed applicable to all situations associated to welding and preparation angles.

In order to reduce the variability of the results, the following processes or changes in the processes used could be completed: 
1. The coupons could be annealed after welding, prior to tensile testing in order to relieve the internal stresses caused by the machining processes and welding.

2. The cooling rate of the welded samples could be controlled so that the welded samples cool at a uniform rate after welding.

3. The welded samples could be X-ray, florescent-penetrant, or magnetic-particle tested prior to tensile testing in order to discard any coupons with defects in the weld.

4. A number of maximum pull results could be discarded when the results fall outside a given range or do not meet defined parameters in order to reduce the standard deviation.

Due to the multi-faceted nature of the welding process, it is inconclusive to be able to isolate one variable as a predictive factor of the mechanical performance of a weld joint. However, a better understanding of each individual elements role can be compiled into a larger knowledge base related to this topic. If any change in one of the multiple variables occurred, a statistically significant difference in obtained information could occur that could offer additional associations to research of this nature.

\section{Recommendations for Further Research}

Based on the experience gained during this research, combined with the analysis of findings and conclusions, the following recommendations for further research are offered:

1. Further study in this area could include reducing the change in included preparation angles to a smaller degree. $10^{\circ}$ increments of the included preparation angle were utilized during this research, and smaller changes in angles may yield results that are less varying.

2. Due to the variability of welding on this material, it is proposed that studies of alternative materials be conducted. Differing materials have different properties, 
which may cause a deviation from the mean tensile strength at different degrees with various materials. As an additional note related to this type of study, the additional variable of surface treatments or coatings could also be assessed.

3. Due to the unique properties of the various types of welding, it is proposed that a type of welding other than MIG welding may yield different results. Although most types of welding yield similar results, the HAZ and other properties of the welded joint may vary.

4. The geometry of the joint may be altered in order to yield dissimilar results. A single-vee butt joint may yield different results than that of a double-vee butt joint, or other joint configuration. 


\section{References}

American Welding Society. (1976). Welding Handbook. Miami, FL: American Welding Society.

ASM International. (1997). Weld Integrity and Performance. Materials Park, OH: ASM International.

Davies, A. C. (1977). The Science and Practice of Welding. Cambridge: Cambridge University Press.

Davies, A. C. (1984). The Science and Practice of Welding. Cambridge: Cambridge University Press.

DeGarmo, E. P., Black, J. T., Kohser, R. A., \& Klamecki, B. E. (2003). Materials and Processes in Manufacturing. Hoboken, NJ: John Wiley \& Sons, Inc.

ESAB North America. (2010). MIG Welding. Retrieved January 17, 2011, from ESAB Welding and Cutting: http://www.esabna.com/euweb/mig_handbook/592mig1_1.htm

Farhat, H. (2007). Effects of Multiple Wires and Welding Speed on the Microstructures and Properties of Submerged Arc Welded X80 Steel. Saskatoon: University of Saskatchewan.

Garson, D. (2008, June 4). Tests for More Than Two Independent Samples: Kruskal-Wallis H, Median, and Jonckheere-Terpstra Tests. Retrieved February 21, 2011, from NC State University: http://faculty.chass.ncsu.edu/garson/PA765/kruskal.htm

Garson, D. (2009, February 6). Univariate GLM, ANOVA, and ANCOVA. Retrieved February 22, 2011, from NC State University: http://faculty.chass.ncsu.edu/garson/PA765/anova.htm Messler, R. W. (1993). Joining of Advanced Materials. Worburn, MA: Butterworth-Heinemann. 
Mott, R. L. (2006). Applied Strength of Materials. Upper Saddle River, NJ: Pearson Prentice Hall.

Norusis, M. J. (2008). SPSS 16.0 Guide to Data Analysis. Upper Saddle River, NJ: Prentice Hall, Inc.

Oberg, E., Jones, F. D., Horton, H. L., \& Ryffel, H. H. (1992). Machinery's Handbook. New York: Industrial Press Inc.

Robert, W. M. (1999). Principles of Welding. New York: John Wiley \& Sons, Inc.

Rossi, B. E. (1954). Welding Engineering. New York: McGraw-Hill Book Company, Inc. 


\section{Appendix A}

Necking Jig Detail Drawings

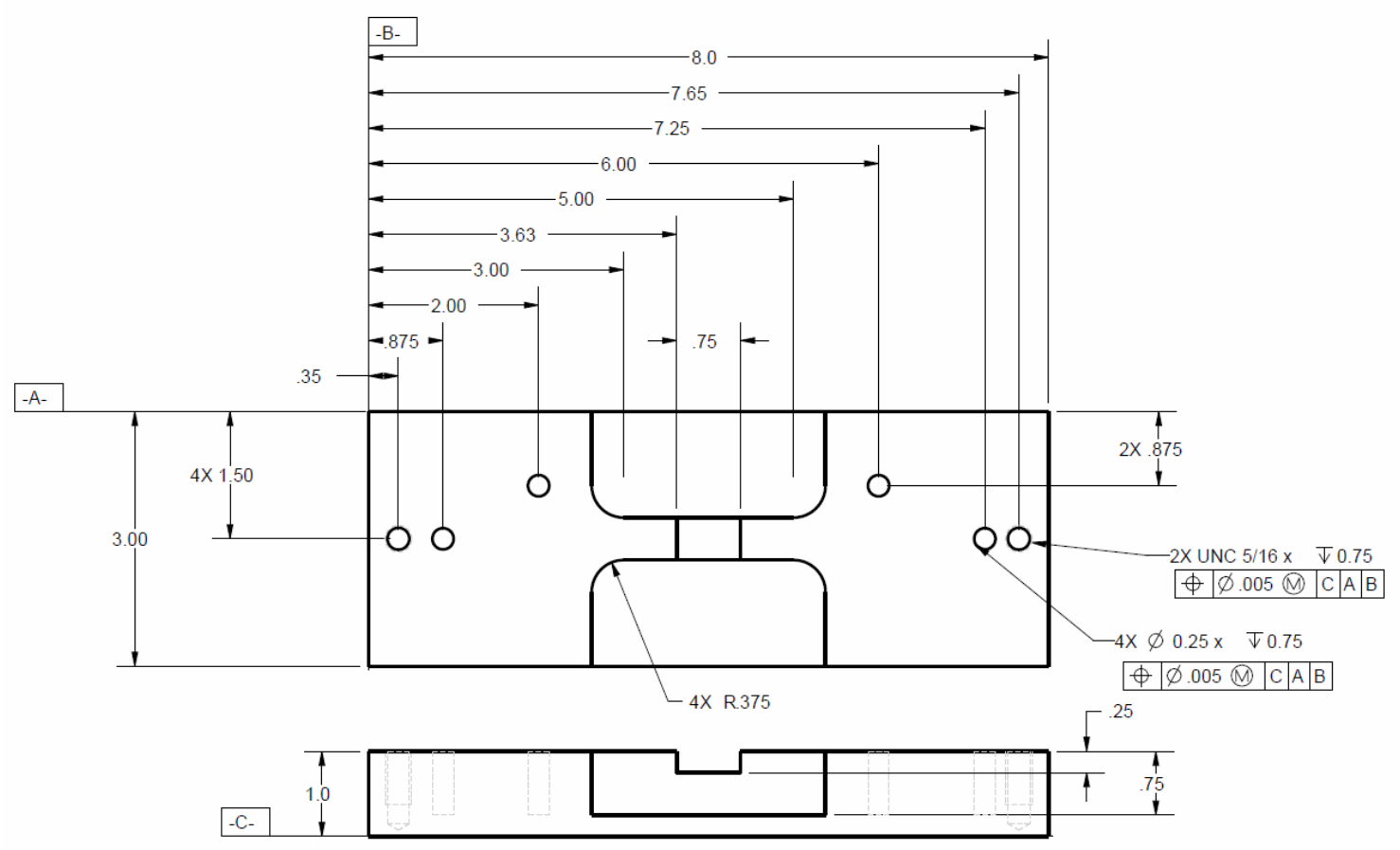

MATERIAL: ASTM A36 STEEL

UNITS IN INCHES

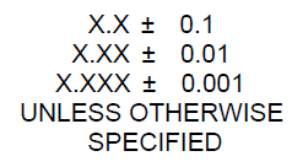

Jig Base

Material $=$ AISI 1018

Quantity $=1$ 

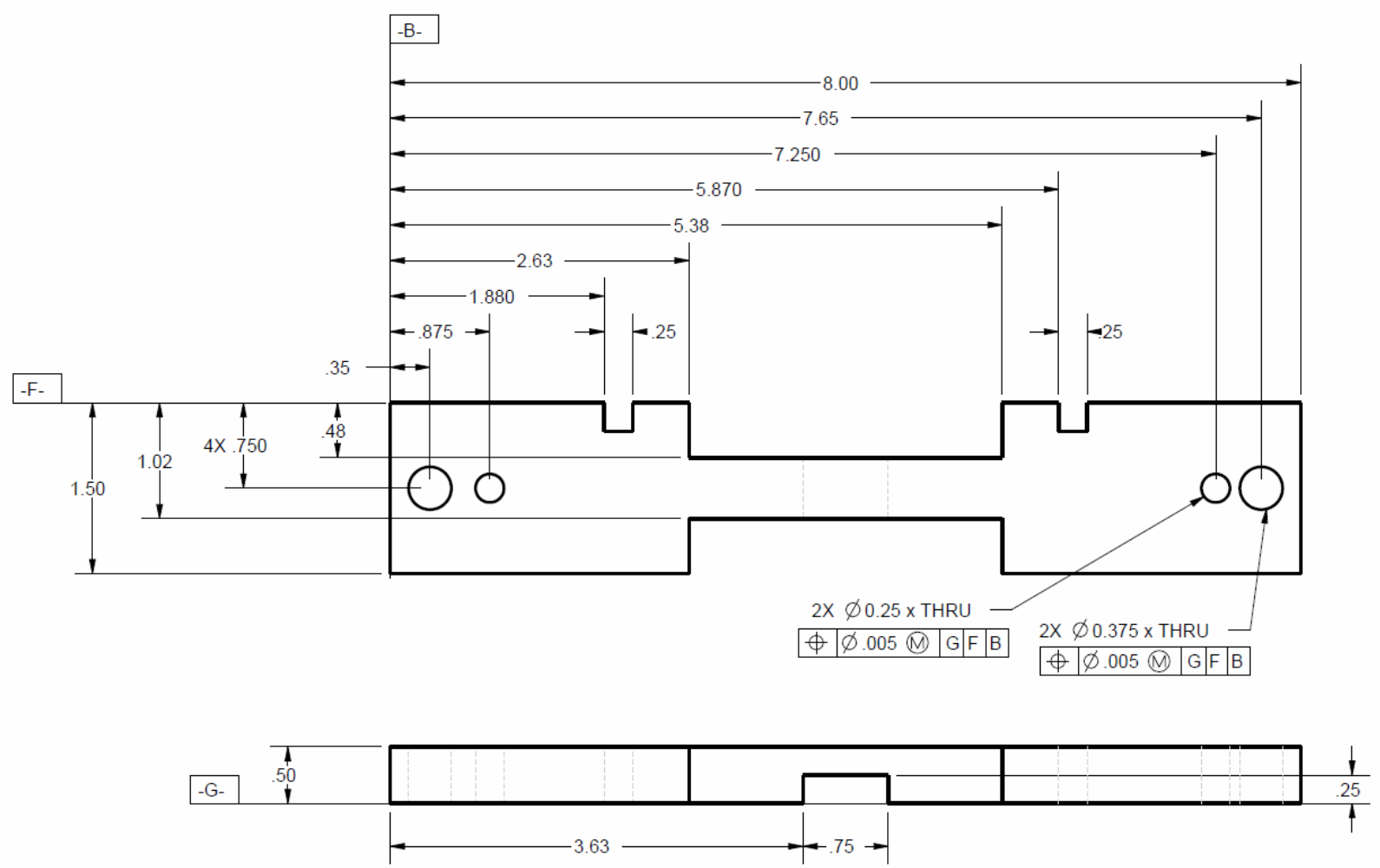

MATERIAL: ASTM A36 STEEL

UNITS IN INCHES

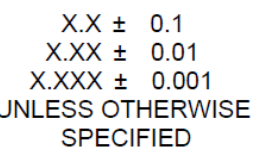

\section{Jig Clamp}

Material $=$ AISI 1018

Quantity = 1 

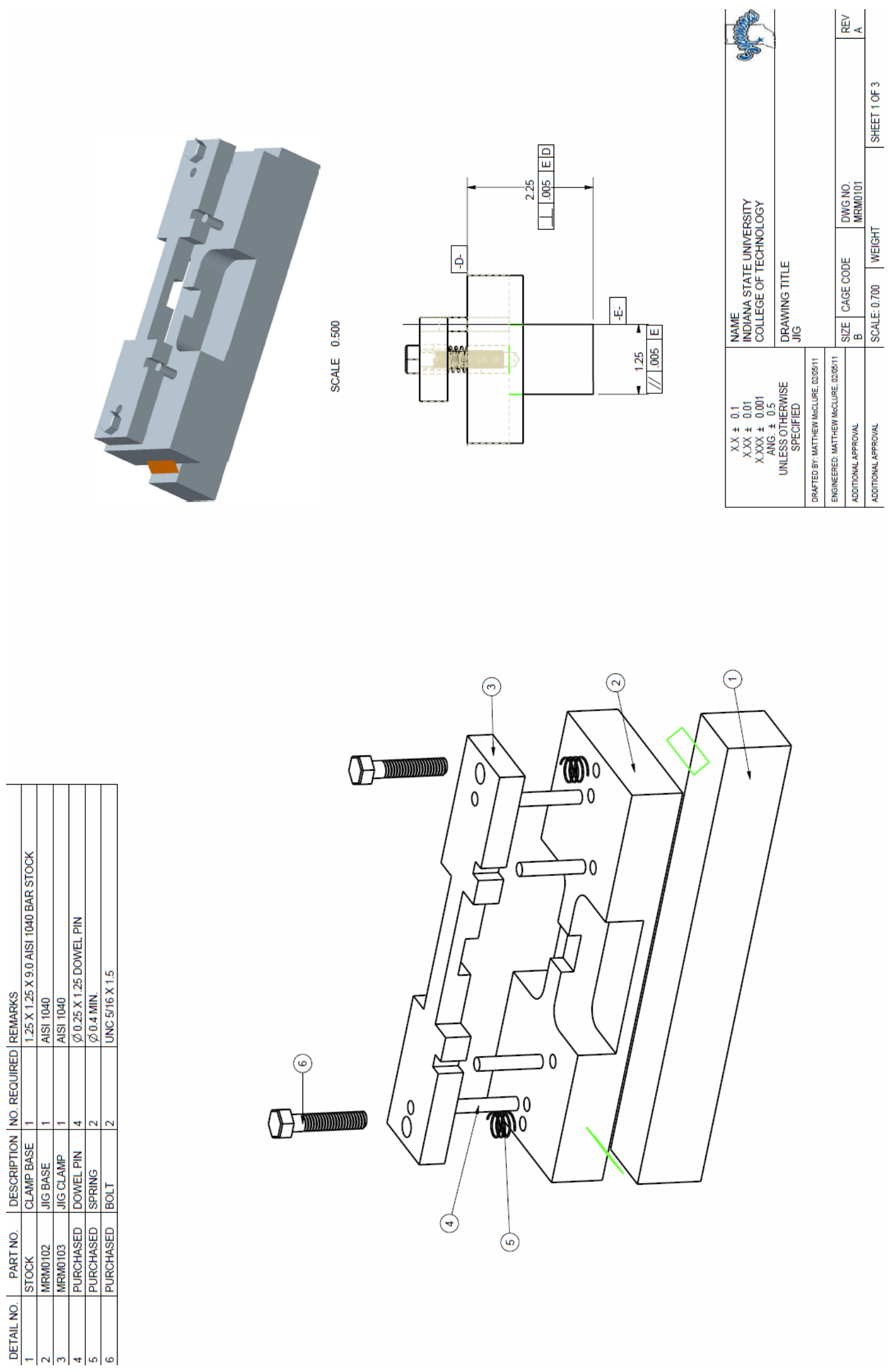


\section{Appendix B}

CNC Code

N102 G90 G80 G40 G20

N105 G15 H4

N106 G0 G90 X4.960 Y-.575

N107 M08

N108 S637 M3

N110 G56 H14 Z.2

N112 G0 Z-.600

N114 G1 Y-.875 F10

N115 X3.040 F10

N116 G0 Z3

N118 G0 Y-2.525

N119 G0 Z-.600

N120 G1 Y-2.125 F10

N121 X4.960

N125 M9

N126 G0 Z9.0

N127 M5

N130 G0 Y2

N266 M30 